\title{
Problemas (y paradojas) actuales de la regulación publicitaria en el ámbito \\ sanitario
}

\section{Actual Problems (and paradoxes) About Advertising Regulation in Health Sscope}

Julio Álvarez Rubio* https://orcid.org/0000-0002-8658-1410

http://dx.doi.org/10.21503/lex.v18i26.2176

* Universidad de Cantabria. Profesor Doctor de Derecho mercantil. Director Académico de la Cátedra Euroamericana de Protección Jurídica de los Consumidores. Presidente de Colegio arbitral de consumo. España.

Correo electrónico: julio.alvarez@unican.es

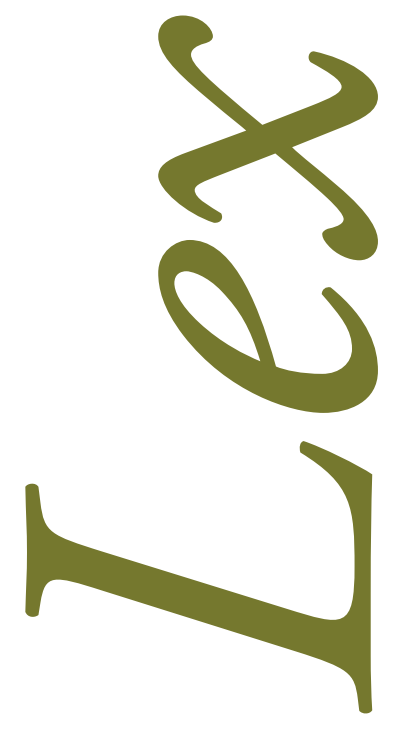
(c) (C) (C) Los autores. Artículo publicado por la Revista Lex de la Facultad de Derecho y Ciencias Políticas de la Universidad Alas 


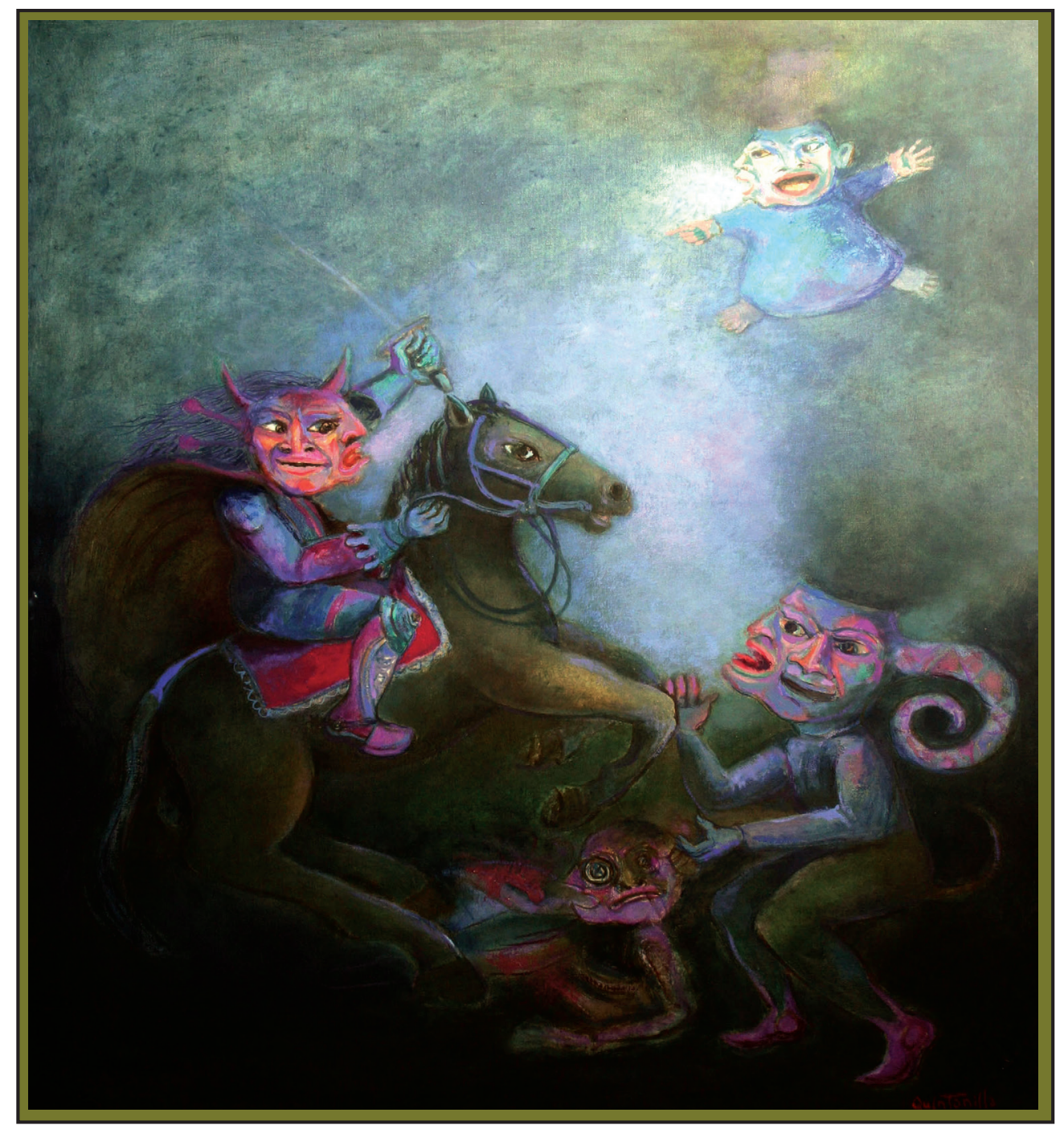

¿Dónde está Santiago? Óleo, 2003. Artista plástico peruano, Alberto Quintanilla (Cusco, 1934). 


\section{RESUMEN}

El trabajo trata sobre la existencia de diferentes tensiones en el ámbito de la regulación de la actividad publicitaria en España. Se analiza cómo, en ocasiones, la vinculación de esa actividad promocional con la protección de la salud sirve para proponer reformas innecesarias en determinados ámbitos que suelen resultar sensibles para determinados intereses económicos corporativos mientras que, en otras, se obvian problemas acuciantes necesitados de regulación urgente precisamente por la existencia de tales intereses y por la escasa capacidad que, para influir políticamente, tienen consumidores y usuarios. Fundamentalmente se analizan los ámbitos de la publicidad de las clínicas dentales, las pseudociencias y el juego.

Palabras clave: publicidad, salud, clínicas dentales, pseudociencias, consumidor, juego, menor de edad.

\section{ABSTRACT}

The study shows how, sometimes, when proposing legislative reforms, economic interests outweigh the defense of unprotected consumers. This is happening recently in Spain, especially in some fields as advertising regulation with some relationship with health. The paper analyzes, specifically, dental clinics advertising, pseudosciences advertising and gambling advertising.

Key words: advertising, health, dental clinics, pseudosciences, consumer, gambling, minor. 


\section{INTRODUCCIÓN}

La publicidad de medicamentos y productos sanitarios requiere, por razones obvias, una regulación específica que prevenga y ataje determinados comportamientos que, en un ámbito promocional y de comercialización de semejantes bienes y servicios, pudieran, eventualmente, afectar al principal bien jurídico protegido, que no es otro que la salud del potencial destinatario de aquellos.

Así, son varias las normas que, desde diferentes puntos de vista en función del objeto regulado y del target al que van dirigidas las comunicaciones comerciales, abordan semejante cuestión en España. De forma central, e independientemente de regulaciones sectoriales o de ámbito territorial más reducido, habría que citar el Real Decreto 1416/1994, de 25 de junio, por el que se regula la publicidad de los medicamentos de uso humano, el Real Decreto Legislativo 1/2015, de 24 de julio, por el que se aprueba el texto refundido de la Ley de garantías y uso racional de los medicamentos y productos sanitarios y el Real Decreto 1907/1996, de 2 de agosto, sobre publicidad y promoción comercial de productos o actividades o servicios con pretendida finalidad sanitaria.

Pareciera, a la luz de las normas referidas, que el sector se encuentra suficientemente regulado y que, combinadas tales normas con otras de carácter más general, como la Ley 34/1988, de 11 de noviembre, General de Publicidad o la 3/1991, de 10 de enero, de Competencia Desleal o, incluso, en función del medio de comunicación utilizado para la difusión del mensaje publicitario, la Ley 7/2010, de 31 de marzo, General de la Comunicación Audiovisual o la Ley 34/2002, de 11 de julio, de Servicios de la Sociedad de la Información y de Comercio Electrónico, el margen de riesgo frente a posibles ilícitos en semejante ámbito es ciertamente escaso.

Sin embargo, en los últimos tiempos, nos encontramos con diferentes cuestiones, todas ellas de gran relevancia mediática, que pudieran hacer pensar, bien que la regulación actual es inexistente o se encuentra desfasada, bien que existen sectores de riesgo que escapan al ámbito de aplicación de las normas comentadas. El presente trabajo pretende abordar, críticamente, estas cuestiones, evidenciando a través de un contraste de las diferentes situaciones planteadas, que muchos de los "escándalos" aparentes que 
motivan intensas reacciones mediáticas son producto, una vez más, de la actuación de lobbies profesionales en defensa de sus intereses corporativos, mientras que, paradójicamente, ámbitos que sí precisan, de forma urgente, de una reacción legislativa decidida y contundente permanecen en un segundo plano de atención, debido al escaso empoderamiento de los colectivos afectados.

Sin ánimo de ser exhaustivos, y teniendo como única referencia la actualidad mediática más inmediata, el análisis podría centrarse en tres escenarios, como son el reiterado intento por parte de determinados partidos políticos nacionales de proceder a una regulación que ataje la publicidad engañosa y el intrusismo en el ámbito de las clínicas dentales, la reciente actuación gubernamental contra las "pseudociencias" y el debate respecto de la necesaria regulación del juego.

\section{PUBLICIDAD DE CLÍNICAS DENTALES: ¿LAGUNA LEGAL O DEFENSA CORPORATIVA?}

A raíz de algún reciente concurso de empresas franquiciadoras de clínicas dentales, hecho que desencadenó, lógicamente, el desamparo de los usuarios de los servicios prestados por tales clínicas, hemos asistido a una recurrente campańa mediática en la que, de forma especialmente virulenta, las asociaciones profesionales del sector denuncian un vacío legal que permite excesos por parte de las compañías afectadas y, en consecuencia, exigen una regulación legal que ponga fin a prácticas, en su opinión, engańosas y desleales ${ }^{1}$.

A este respecto cabría plantearse, primero de todo, si efectivamente existe la laguna legal denunciada. ¿Permite la legislación, sectorial o general, realizar comunicaciones comerciales no veraces o confusionistas? Pues bien, un mero repaso a las normas aplicables es suficiente para contestar, sin margen de error, a la pregunta planteada.

Por comenzar con la norma general, la Ley 3/1991, de 10 de enero, de competencia desleal (en adelante LCD), se muestra contundente respecto de la prohibición de comportamientos engañosos en el ámbito de la comercialización de bienes y servicios: así, su art. 5 señala que "se considera desleal por engañosa cualquier conducta que contenga información falsa o información que, aun siendo veraz, por su contenido o presentación induzca o pueda inducir a error a los destinatarios, siendo susceptible de alterar su comportamiento económico (...)". Este precepto elimina el riesgo que podrían generar, no sólo prácticas publicitarias engańosas que, de forma directa, realicen afirmaciones falsas o inexactas en

1. Nota de prensa del Colegio de Dentistas de Gipuzkoa, acceso el 20 de junio de 2020, file://C:/Users/alvarej/Down loads/Ndp_12jun2014_definitivo.pdf, en donde, de forma expresa, se afirma que "en Francia, Alemania y Bélgica la publicidad sanitaria está prohibida o estrictamente regulada”, como si, contrario sensu, en España no lo estuviera... comunicado del Colegio oficial de dentistas de Las Palmas, acceso el 28 de mayo de 2020,

https://coelp.es/78-menu/573-ojo-con-la-publicidad-enganosa.html; foro sobre "La mercantilización de la Odontología: un problema de salud pública”, organizado por el Colegio Oficial de Odontólogos y Estomatólogos de Madrid (nota de prensa), acceso del 4 de julio de 2020 , https://www.coem.org.es/media/page/prensa/NP_Observatorio_profesion151217.pdf, etc. 
relación con el bien promocionado, sino también el de aquellas otras que, sin incurrir en una falsedad evidente, presenten el mensaje de forma interesada o ventajista, abusando de la letra pequeńa o de asteriscos estratégicamente situados, buscando provocar una impresión errónea en el potencial destinatario de la comunicación comercial, por mucho que el mensaje, leído en su totalidad y de forma detenida, pudiera corresponderse con la realidad.

En concreto, y por relacionar lo previsto en el precepto con la casuística denunciada en el supuesto ahora estudiado, el artículo considera la actuación empresarial engañosa cuando esta tenga que ver con alguno de los siguientes aspectos: características principales del bien o servicio, tales como sus beneficios, sus riesgos, su ejecución o los resultados que pueden esperarse de su utilización; la asistencia posventa al cliente y el tratamiento de las reclamaciones; el alcance de los compromisos del empresario o profesional y la naturaleza de la operación comercial o el contrato; el precio o su modo de fijación, o la existencia de una ventaja específica con respecto al precio; la naturaleza, las características y los derechos del profesional, tales como su identidad y su solvencia, sus cualificaciones, su situación, su aprobación, su afiliación o sus conexiones; los riesgos que el consumidor pueda correr, etc. Como se puede comprobar, este resumen de las circunstancias sobre las que puede recaer la carga engañosa de la comunicación abarcan la práctica totalidad de las conductas que se han reprochado a las clínicas dentales afectadas por las diferentes denuncias, como son falsedad u oscuridad en la determinación del precio final del servicio, la ocultación o frivolización acerca de los posibles riesgos asumidos, el intrusismo profesional, las garantías de resultado, el engaño acerca de la forma de pago, etc.

La mera aplicación de este precepto de la LCD supondría la erradicación de las prácticas denunciadas, en el supuesto de que éstas, efectivamente, pudiesen afectar al comportamiento económico del cliente. Además, la propia LCD, en su art. 7, prevé que la posible deslealtad de la comunicación comercial se derive, ya no de la inclusión de elementos engañosos en el mensaje, sino de la "omisión u ocultación de la información necesaria para que el destinatario adopte o pueda adoptar una decisión relativa a su comportamiento económico con el debido conocimiento de causa", lo que bien pudiera atajar también otras conductas que inducían al consumidor a contratar el servicio ocultándole la verdadera naturaleza de la proposición comercial realizada o el alcance real del compromiso que asumía al aceptar la prestación.

Incluso, fuera ya del ámbito estricto de la publicidad engañosa, posibles prácticas tramitadas de forma irregular o directamente ilícita y utilizadas en la promoción de los servicios ofertados, como pudiera ser el millón de euros con el que, supuestamente, iDental subvencionaba sus tratamientos (no consta la existencia de su formalización como tal subvención o la naturaleza de ONG o fundación de la organización "donante"...), podrían incurrir también en competencia desleal de la mano del art. 15 de la norma, que considera desleal "prevalerse en el mercado de una ventaja competitiva adquirida mediante la infracción de las leyes".

Y, asimismo, la venta por debajo del precio de adquisición de determinados productos sanitarios 
utilizados en los tratamientos ofertados, también serían declarados desleales al aplicar el art. 17.2.a) de la LCD, siempre y cuando esos precios fueran susceptibles de inducir a error a los consumidores acerca del nivel de precios de otros productos o servicios del mismo establecimiento, lo cual resulta bastante previsible en supuestos como algunos de los denunciados (implantes dentales promocionados bajo precios muy reducidos ${ }^{2}$ omitiendo el coste del resto del tratamiento, de coste similar o incluso superior al ofertado por establecimientos de la competencia).

Parece bastante obvio, a la luz de lo reseńado, que el régimen jurídico general de la publicidad como principal arma concurrencial, resulta suficiente para abortar la mayoría de las prácticas mencionadas como abusivas o irregulares al socaire de los últimos escándalos detectados.

Pero, por si la norma general resultase poco explícita o, si se quiere, no demasiado específica, el Real Decreto 1907/1996, de 2 de agosto, sobre publicidad y promoción comercial de productos, actividades o servicios con pretendida finalidad sanitaria, también incorpora normas que resultan plenamente aplicables a los casos que ahora se estudian. Así, el art. 7 del RD establece, de forma clara, que "toda información, publicidad o promoción comercial a que se refiere este Real Decreto deberá ajustarse a criterios de transparencia, exactitud y veracidad y evitará cualquier sesgo que pueda causar perjuicio a la salud o seguridad de las personas o a las legítimas expectativas de una información correcta y precisa en materia de salud y asistencia sanitaria”, conminando a los medios de comunicación a no admitir comunicaciones comerciales contrarias a los dispuesto en la norma.

Asimismo, en el art. 4, se prohíben expresamente las prácticas promocionales que "pretendan aportar testimonios de profesionales sanitarios, de personas famosas o conocidas por el público o de pacientes reales o supuestos, como medio de inducción al consumo", lo que, debidamente aplicado, supone la retirada y eventual sanción de aquellas comunicaciones comerciales, tan frecuentes en el ámbito ahora analizado, que utilizan publicidad "testimonial" de celebridades del espectáculo o el deporte para anunciar servicios sanitarios ${ }^{3}$.

2. A este respecto, cabría plantearse, incluso, si tal publicidad es admisible de acuerdo con el art. 80.7 de la Ley de Garantías y Uso Racional de los medicamentos y productos sanitarios, que señala que "no podrán ser objeto de publicidad destinada al público los productos sanitarios que estén destinados a ser utilizados o aplicados exclusivamente por profesionales sanitarios". En contra, la Sentencia del Juzgado de lo Mercantil núm. 3 de Valencia, de 20 de marzo de 2018 (AC 2018\1092), aunque con un argumento que, lejos de analizar la adecuada interpretación del precepto, se limita a evidenciar la fáctica ausencia de prohibición por parte de la Administración competente.

3. Acudiendo a la praxis, nos encontramos con la suspensión que la Dirección General de Planificación, Investigación, Farmacia y Atención al Ciudadano de la Consejería de Sanidad de Murcia procedió a aplicar a sendas comunicaciones comerciales de las clínicas Dentix y Avantdent en la provincia y en la ciudad de Murcia, respectivamente, "hasta que se subsanen los defectos o se cumplan los requisitos exigidos", tras aceptar las denuncias interpuestas el Colegio de Dentistas de la Región. Resulta habitual la utilización en las campañas publicitarias, por parte de Dentix, de personales célebres en el mundo del espectáculo y del deporte, como Cristina Pedroche, Figo, Xavi, Iker Casillas o Andrés Iniesta. Portal PRNOTICIAS, 3 de agosto de 2016, acceso el 10 de junio de 2020,

https://prnoticias.com/marketing/espacio-marketing/20155174-dentix-retirada-publicidad-en-murcia.

Pero los ejemplos exceden del ámbito puramente administrativo. Así, la Sentencia del Tribunal Superior de Justicia de 
Incluso otro de los preceptos que pudiera resultar menos explícito, como es el que establece que "la publicidad y la información de los centros o establecimientos sanitarios y de los centros de belleza, adelgazamiento, tratamiento o desarrollo físico o estético, así como de los servicios y prestaciones que realizan deberá ajustarse al contenido de la autorización sanitaria de tales centros o establecimientos" (art. 6.1 del RD) pudiera perfectamente servir para vetar aquellas tácticas promocionales, también denunciadas en múltiples ocasiones por el colectivo de colegios profesionales del sector, que utilizan primas y regalos como acicate para incentivar la contratación de los servicios bucodentales ofertados ${ }^{4}$. Resulta obvio que la autorización sanitaria dispensada por la Administración competente se ceñirá a las actividades profesionales que el centro prevé desarrollar, sin que en las mismas se incluyan la dispensación de artículos de ocio o la prestación de servicios de carácter lúdico que pudieran reforzar la comercialización de aquellos, para lo cual la propia norma exige una nueva, expresa y previa autorización (art. 6.2).

Por si la referencia comentada no fuera suficiente, incluso podría invocarse, por analogía con el bien jurídico protegido, que no es otro que la salud de los potenciales consumidores y usuarios, lo dispuesto, esta vez de forma expresa, en el art. 80.5 del Real Decreto Legislativo 1/2015, de 24 de julio, por el que se aprueba el texto refundido de la Ley de garantías y uso racional de los medicamentos y pro-

Navarra (Sala de lo Contencioso-Administrativo, Sección1ª), de 14 de marzo de 2017 (JUR 2017\225689), corrige la sentencia de instancia y señala: "Pues bien, en el presente caso, la autorización solicitada por la entidad "Dentoestetic, Centro de Salud y Estética Dental, S.L." lo fue para la difusión de publicidad sanitaria consistente en un folleto en el que aparecen dos futbolistas famosos bajo cuya imagen se recoge el siguiente texto: "Hemos llevado a Eloy a una peña de aficionados al fútbol para que explique el Método Dentix. Y por muy Eloy que sea se convencen. Porque tiene sentido". Igualmente consta una fotografía de un famoso exfutbolista bajo cuya imagen se recoge el siguiente texto: "El Método Dentix convence a todo el mundo. Porque tiene sentido. Implantología dental desde 222 euros".

Y en el reverso se hace referencia al Método Dentix (Clínica propias no franquiciadas, equipo $360^{\circ}$ : equipo integral que ofrece todos los servicios necesarios, más implantes menor precio, y tecnología vanguardista. También se hace referencia al precio de Ortodoncia y la Implantología dental (aclarando qué son los implantes).

Es evidente que se está utilizando la imagen de dos personas famosas para publicitar, no sólo el método empleado por dicha empresa, sino también un producto sanitario; imagen que por sí sola ya constituye publicidad a tenor de lo dispuesto en el artículo 1 del Decreto Foral 203/1997 ("a los efectos de la presente disposición se entiende por publicidad directa al público de productos sanitarios, toda forma de comunicación gráfica, sonora o audiovisual, efectuada en cualquier soporte, realizada por personas físicas o jurídicas dirigida a promover, directa o indirectamente, la venta o el uso de productos sanitarios")." Como se puede observar, la resolución judicial es clara y contundente, y corrige el pronunciamiento del tribunal de instancia que, sin perjuicio de reconocer la naturaleza de producto sanitario de los implantes ofertados, consideraba, en una muy singular interpretación, que "en el presente caso no existe recomendación de dicho producto sanitario, no incurriéndose en la prohibición establecida en dicho texto legal al considerar que los jugadores cuya imagen aparece en el folleto no hacen recomendación alguna, limitándose a posar sonrientes. Y que el contenido de la publicidad se limita a describir el "método dentix". En definitiva, declara que "la publicidad firmada por Dentix incide en factores empresariales pero no sanitarios y por tanto, no incurre en recomendación prohibida alguna”.

4. “Tú no puedes supeditar un tratamiento de ortodoncia, o de implantología, a que te regalen una tablet o los libros de texto de tus hijos, o a que te den una hamburguesa solo por visitar al dentista. El paciente tiene que pagar por lo que recibe y tiene todo el derecho a conocer el presupuesto final". Declaraciones de Oscar Castro, Presidente del Consejo General de Dentistas de España en el diario La Verdad, acceso el 6 de julio de 2020, https://www.laverdad.es/murcia/ colegio-paro-denunciar-20190310003103-ntvo.html. 
ductos sanitarios (en adelante LGURM), que señala que "se prohíben las primas, obsequios, premios, concursos, bonificaciones o similares como métodos vinculados a la promoción o venta al público de estos medicamentos" (en similar sentido, respecto de los productos sanitarios financiados por el sistema nacional de salud, el art. 80.6 in fine).

Por último, y por terminar de repasar las disposiciones que, de forma directa o indirecta, pudieran coadyuvar a controlar practicas promocionales perniciosas en el sector odontológico, es preciso contemplar también lo reseñado en el art. 80.8 de la LGURM, que establece que "la publicidad de las técnicas o procedimientos médicos o quirúrgicos ligados a la utilización de productos sanitarios específicos respetará los criterios contemplados en la publicidad de productos sanitarios". Pues bien, si observamos la definición de producto sanitario de la que parte semejante norma, que entiende por tal a cualquier instrumento, dispositivo, equipo, programa informático, material u otro artículo, utilizado solo o en combinación, incluidos los programas informáticos destinados por su fabricante a finalidades específicas de diagnóstico y/o terapia y que intervengan en su buen funcionamiento, destinado por el fabricante a ser utilizado en seres humanos con fines de: $1 .^{\circ}$ Diagnóstico, prevención, control, tratamiento o alivio de una enfermedad; $2 .^{\circ}$ diagnóstico, control, tratamiento, alivio o compensación de una lesión o de una deficiencia (...), resulta evidente que las comunicaciones comerciales que promocionen tratamientos de implantes dentales, técnicas de ortodoncia o intervenciones de estética dental, entre otras, se encontrarían dentro del ámbito de aplicación de la norma, lo cual refuerza el control a que se encuentran sometidas tales prácticas publicitarias ${ }^{5}$.

Parece, en definitiva, que sí existen normas lo suficientemente concretas como para controlar posibles prácticas publicitarias desleales, bien sean éstas engañosas, confusionistas o, incluso, agresivas, en el ámbito sanitario y pseudosanitario ${ }^{6}$. El problema quizás sea la deficiente aplicación de las mismas,

5. A este respecto, conviene recordar que Dentix ha recurrido ante el Tribunal Supremo la Sentencia del TSJ de Navarra (ver nota 4), en un intento por excluir a la odontología de la consideración de producto sanitario, para, de esa forma, obviar la prohibición legal existente y seguir realizando publicidad "testimonial". La compañía considera que "si las prohibiciones van referidas a publicidad de productos sanitarios no se debe ampliar la prohibición a la publicidad de servicios dentales de implantología, ortodoncia, etcétera, por lo que Dentix sí podría llevar a cabo dicha publicidad". Portal LA INFORMACIÖN, 24 de junio de 2018, acceso el 2 de junio de 2020,

https://www.lainformacion.com/empresas/el-ts-analizara-anuncios-de-implantes-dentales-de-iniesta-xavicasillas-y-figo/6350946/.

6. El Colegio Oficial de Odontólogos y Estomatólogos de Valencia, en su campaña informativa acerca de las prácticas engañosas más habituales, señala:

"No se fíe de cualquier publicidad de clínicas dentales. En ocasiones, dicha publicidad puede ser éticamente engañosa. Por eje. - Cuando le prometen un resultado determinado desde el principio (es imposible asegurar que un tratamiento siempre irá bien al 100\%). - Cuando le dan garantía de por vida en los implantes o las prótesis (es imposible que un implante o una prótesis dure ilimitadamente en la boca del paciente). - Cuando se promociona con un precio escandalosamente bajo como gancho y luego en el presupuesto ese precio sólo corresponde a una parte del tratamiento (Ej. implantes). De esta forma el precio final se acaba multiplicando hasta seis veces más ya que se incluyen el resto de fases no citadas (Ej.: corona, cirugía, revisiones, etc)." Acceso el 7 de junio de 2020, http://www.icoev.es/portal-ciudadanos/ publicidad-enganosa/. 
siquiera de oficio en el ámbito administrativo, pues ya hemos comprobado como la respuesta de la Administración y de los Tribunales a instancia de parte es positiva y aplica de forma satisfactoria las normas existentes ${ }^{7}$.

Es curioso, y significativo al tiempo, que aluda a tres ejemplos que, todos ellos, están suficientemente previstos en las normas generales y sectoriales aplicables al sector: la garantía de resultado (art. 6.1.b del RD 1416/1994, de 25 de junio, por el que se regula la publicidad de los medicamentos de uso humano, entendiendo "medicamento" lato sensu), los actos de engaño (art. 5 LCD) y las omisiones engañosas (art. 7 LCD).

De hecho, como prueba evidente de la vigencia y aplicación de semejantes normas, destacar que en la propia Comunidad Valenciana, la Audiencia Provincial ha confirmado recientemente (SAP de Valencia, sección 9a de 28 de marzo de 2019, -JUR 2019\154089), la sentencia del Juzgado de lo Mercantil núm. 3 de Valencia,, de 20 de marzo de 2018 (AC 2018\1092), la cual concluía, en relación con una campaña publicitaria particularmente agresiva de un conocido odontólogo lo siguiente: "Atendida la prueba practicada, e incluso al margen de la carga probatoria que se considera que el demandado no ha cumplido, puede concluirse que las afirmaciones realizadas por el Dr. Florián en las diferentes notas de empresa remitidas a los medios de comunicación y relativas a sus características profesionales no eran ciertas. Los informes aportados como doc. 12 de la demanda, han sido más que suficientes para alcanzar una convicción final y sin género de duda que las afirmaciones del demandado y publicitadas en los diferentes medios de comunicación, (afirmando que realiza intervenciones pioneras, que es un pionero sobre implantes sin injertos, que es un descubridor de nuevas técnicas de implantes maxilofaciales sin injertos que facilitan la rehabilitación total de los pacientes, etc...), no son ciertas, pues las técnicas a que se refiere datan ya desde los años 80 . Pero incluso atribuyéndole la autoría de la técnica de predicción PARP, tampoco este descubrimiento le sitúa en la élite internacional de la implantología dental, ni se trata de un avance científico reconocido, ninguna prueba se aporta al respecto por el Dr. Florián más allá de certificados emitidos por casas comerciales y empresas privadas, y participaciones en eventos ligados a dichas casas comerciales, frente al informe pericial elaborado por el Dr. Paulino o el informe emitido por la Sociedad Española de Cirugía Bucal; incluso de las testificales practicadas en el acto del juicio, se reconoce que es un sistema que a los profesionales más expertos les aporta poco.

Es por todo lo anteriormente expuesto, por lo que se considera que procede la estimación parcial de la demanda, pues si bien no se ha estimado la pretensión de que se declare que la publicidad de procedimientos y técnicas ligadas a la utilización de implantes dentales está prohibida legalmente, sí se estima la pretensión de que se declare que la publicidad llevada a cabo por el Dr. Florián en los distintos medios de comunicación, y relacionados con el sistema de predicción PARP y cualidades profesionales del demandado, es publicidad engañosa y desleal, por lo que el demandado no sólo debe cesar definitivamente en dicha publicidad, sino que debe corregir por completo sus anuncios publicitarios porque ha resultado acreditado en este juicio que dicha publicidad es engañosa y desleal, y con ello ha generado confusión en los consumidores al mostrar una imagen suya de excelencia profesional que era falsa, de tal manera que dichos anuncios sí son susceptibles de inducir a los consumidores a contratar sus servicios en la creencia errónea de que forma parte de la élite internacional en materia implantología dental, como si fuera uno de los pocos profesionales que usan y conocen dicha técnica, o que ha descubierto una técnica que le sitúa por encima o en grupo muy reducido de profesionales a nivel internacional, cuando estas circunstancias se ha considerado acreditado que son falsas, y que la finalidad de dichos anuncios o campaña publicitaria era la captación de clientela”.

7. Ver nota 4. En similar sentido obsérvese la sentencia de la Audiencia Provincial de Madrid (Sección $28^{\text {a }}$ ), de 28 de noviembre de 2016 (JUR 2017\76885), cuya valoración en relación con la eventual deslealtad, por engañosa, de una alegación publicitaria de una clínica dental, merece ser reproducida íntegramente a fin de comprobar la abundancia de argumentos, tanto procesales como materiales, que permiten al juzgador construir sus fundamentos: "28.- La sentencia de instancia considera que el eslogan publicitario "por eso empleamos lo último en tecnología de implantología, para que recuperes toda la funcionalidad y estética de tu boca en un solo día” es publicidad engañosa en el sentido a que se refiere el artículo 3 e) de la Ley 34/1988, de 11 de noviembre ( RCL 1988, 2279 ) , General de Publicidad (en adelante LGP ( RCL 2003, 2753 ) ) en relación con el artículo 5 de la Ley 3/1991, de 10 de enero, de Competencia Desleal (en adelante LCD ( RCL 1991, 71 ) ) 
29.- La juez "a quo" considera que la valoración conjunta de las periciales practicadas y los testimonios de los testigos-peritos conducen a la conclusión de que todos ellos consideran que no es posible efectuar la implantología en un solo día, con la salvedad de don Vicente.

30.- Asimismo, la juzgadora de instancia entiende que no ha quedado acreditado que VITALDENT haya prestado el servicio de realización de un implante en un solo día.

31.- Frente a tales conclusiones VITALDENT mantiene que el tratamiento ofertado no es propio de dicha compañía, sino que se trata de una técnica quirúrgica denominada de carga o función inmediata. Esta técnica es una evolución de la denominada "all on four", que se encuentra en el folleto del fabricante Nobel Biocare. La ventaja de esta técnica consiste en que una vez insertado el implante dentro del lecho óseo, se coloca la prótesis en un tiempo inferior a las 24 horas (informe pericial de don Vicente).

32.- VITALDENT mantiene que la valoración de la prueba testifical-pericial y pericial conduce a la conclusión de que sí es posible realizar el tratamiento ofertado el mismo día, a pesar de que algún autor considere que no es recomendable (página 13 del recurso)

33.- Para justificar este aserto, VITALDENT introduce una variación importante a su planteamiento inicial, pues en el recurso se indica que la recuperación de la funcionalidad y estética de la dentadura se recupera con la colocación de una prótesis provisional. Al respecto puntualiza que en ningún momento la publicidad cuestionada hablaba de la colocación de prótesis provisionales o definitivas. (página 14 del recurso)

34.- Esta distinción entre prótesis provisional y definitiva, así como el análisis de lo que el consumidor medio podría interpretar al respecto con la lectura del eslogan publicitario cuestionado no quedó planteada en esos términos en la fase alegatoria del proceso. Por este motivo el COLEGIO DE LA PRIMERA REGIÓN solicita que sea considerado una cuestión nueva.

35.- En efecto, se trata de un planteamiento novedoso, que debió formularse en tiempo que permitiese su sometimiento al principio de contradicción y correspondiente prueba (es decir, en la fase de alegaciones de la primera instancia, donde han de delimitarse los términos del debate que constituye el objeto del proceso - artículos 399, 400, 412 y 426 de la LEC (RCL 2000, 34, 962 y RCL 2001, 1892)). La prohibición de la mutación de la pretensión (mutatio libeli) tiene como fundamento histórico la proscripción de la indefensión (sentencias del Tribunal Supremo de 26 de diciembre de 1997 y 12 de marzo de 2008 u 8 de junio de 2016, entre otras muchas).

36.- Sea como fuere, este planteamiento de VITALDENT no resulta convincente si tenemos en cuenta el criterio que hemos mantenido en anteriores ocasiones, en sentencias de esta Sección 28 a de la Audiencia Provincial del Madrid de 6 de mayo de 2011, con arreglo al cual, no resulta necesario, para calificar el supuesto de publicidad engañosa, que la información suministrada sea inexacta o inveraz, toda vez que también partiendo de datos verídicos puede inducirse a error. 37.- La publicidad es también engañosa si silencian datos fundamentales de los bienes, actividades o servicios publicitados, cuando dicha omisión induzca a error a sus destinatarios. Se habla, así, usualmente, de publicidad engañosa en forma positiva y de publicidad engañosa en forma negativa, para hacer referencia, respectivamente, a las situaciones en que el error del destinatario viene inducido por la información suministrada y aquellas otras en que el error proviene de la información que no se suministra.

38.- El artículo 5 LCD acoge claramente esta modalidad de engaño por omisión al considerar desleal no solo la conducta que contenga información falsa sino también aquella que contiene información veraz, pero que, por su contenido o presentación, induzca o pueda inducir a error a los destinatarios.

39.- Este precepto responde al criterio establecido en el artículo 7 de la Directiva 2005/29/CE (LCEur 2005, 1143) del Parlamento Europeo y del Consejo, a cuyo tenor “ 1 . Se considerará engañosa toda práctica comercial que, en su contexto fáctico, teniendo en cuenta todas sus características y circunstancias y las limitaciones del medio de comunicación, omita información sustancial que necesite el consumidor medio, según el contexto, para tomar una decisión sobre una transacción con el debido conocimiento de causa y que, en consecuencia, haga o pueda hacer que el consumidor medio tome una decisión sobre una transacción que de otro modo no hubiera tomado".

40.- En cualquier caso, la aptitud para inducir a error del mensaje publicitario cuestionado ha de ser apreciada en relación con el consumidor tipo, entendiendo por tal, según caracterización común, el consumidor medio, normalmente informado y razonablemente atento y perspicaz, concepto este que aún puede aquilatarse más, siguiendo el criterio 
De hecho, si se observan detenidamente las "quejas" de los diferentes colegios profesionales, se ad-

positivizado en la Directiva 2005/29/CE del Parlamento Europeo y del Consejo, de 11 de mayo de 2005, relativa a las prácticas comerciales desleales de las empresas en sus relaciones con los consumidores del mercado interior, como "consumidor medio al que afecte o se dirija la práctica" y como "miembro medio del grupo, si se trata de una práctica comercial dirigida a un grupo concreto de consumidores".

41.- El análisis de si la publicidad desborda la frontera de lo lícito para merecer el calificativo de engañosa exige examinar el anuncio en su conjunto, sin descomponerlo en partes, situándolo en el contexto social, económico y cultural al que se dirige la promoción publicitaria y teniendo en cuenta el punto de vista del destinatario, entendido como consumidor medio, que es aquél normalmente informado y razonablemente atento y perspicaz (como lo define la jurisprudencia europea en materia de competencia desleal y de publicidad, a partir de la sentencia del TJCE de 16 de julio de 1998 )

42.- El hecho de que VITALDENT no especificara en su publicidad que la prótesis a implantar iba a ser provisional no puede convertirse en un argumento exoneratorio de su conducta, porque precisamente lo que cabe imputar al anunciante es no haberlo especificado, siendo un aspecto muy relevante para que el consumidor medio pudiera entender mínimamente el tratamiento ofertado.

43.- Esta especificación era importante para que el consumidor pudiera adquirir un correcto conocimiento, siquiera fuera en términos generales, de lo que se puede realizar en un día. Este aspecto temporal de un día, fue el eje del mensaje publicitario. De ahí la importancia de la especificación.

44.- Lo que está claro es que no es posible colocar una prótesis definitiva en un solo día, pues así se desprende de las periciales y de los testigos-peritos que han declarado, y lo viene a reconocer ahora VITALDENT. El mensaje publicitario impugnado, sin embargo, resulta claramente confuso sobre este extremo tan relevante y en consecuencia, hemos de considerarlo engañoso. No es necesario para ello acreditar que el engaño se haya producido de modo efectivo en todos o en un grupo significativo de consumidores. Basta la mera potencialidad de que tal engaño pueda afectar al comportamiento económico de los consumidores, tal y como ha remarcado la jurisprudencia (STS de 25 de abril de 2006)

45.- Aparte de esta cuestión tan relevante, parece también incuestionable que la primera visita no puede ser la de la intervención quirúrgica para la implantación de la prótesis provisional. Son necesarias visitas previas para tomar medidas y obtener moldes, tal y como manifestó el testigo-perito don Gonzalo. El perito Julián también resaltó la necesidad de hacer estudios previos y en el mismo sentido se pronunció don Mateo.

46.- Tampoco es una cuestión acreditada que la funcionalidad se adquiera de un modo completo el día de la intervención quirúrgica y así lo aseveró el testigo perito Sr. Gonzalo y el perito don Julián.

47.- VITALDENT combate asimismo el pronunciamiento de la sentencia que considera no acreditado que esta empresa haya utilizado esta técnica de carga inmediata de modo efectivo. A tal efecto invoca la declaración de don Vicente, que señala que todas o gran parte de las clínicas de VITALDENT están capacitadas para aplicar esta técnica y, de hecho, dicho técnico afirma haber realizado este tipo de intervenciones en las clínicas de VITALDENT.

48.- Frente a este razonamiento, los apelados argumentan que el Sr. Vicente fue objeto de tacha por tratarse de un trabajador de VITALDENT y que en su informe no se aporta evidencia alguna de que las clínicas de la apelante tengan capacidad de realizar esta técnica o que se haya utilizado de modo efectivo.

49.- Hemos de recordar, tal y como afirman las apeladas, que en los procesos sobre competencia desleal y sobre publicidad ilícita corresponderá al demandado la carga de la prueba de la exactitud y veracidad de las indicaciones y manifestaciones realizadas y de los datos materiales que la publicidad exprese, respectivamente (art. 217.4 LEC).

50.- También convenimos con los apelados que la simple manifestación del Sr. Vicente, trabajador de VITALDENT, sobre la capacidad de sus clínicas para la realización de la técnica de carga inmediata, desprovista de cualquier otra evidencia, no tiene la suficiente fuerza de convicción como para estimar acreditado este extremo. Compartimos, por tanto, el criterio que sostiene la juez "a quo" sobre el particular.

51.- Por todo lo expuesto, concluimos que concurren los requisitos expresados en el artículo 5 LCD para considerar engañosa la publicidad, a saber, que el mensaje publicitario induzca a error al consumidor medio de cualquier manera, incluida su presentación; y que sea idóneo para afectar al comportamiento económico de sus destinatarios.

52.- Compartimos, por tanto, al igual que la juzgadora de primera instancia, las conclusiones que sobre el particular emitió el jurado de Autocontrol en fecha 20 de febrero de 2012. 
vierte que el verdadero problema no es tanto la publicidad como una posible actividad concurrencial deficientemente regulada, tanto en el acceso a la misma profesión, como en la desvinculación del negocio del carácter profesional de la actividad asistencial ${ }^{8}$.

No beneficia a las, en muchos casos, legítimas aspiraciones del colectivo, este totum revolutum de reclamaciones, las cuales, de alguna forma, se trasladan a las caóticas propuestas de algunos grupos políticos sensibles a las presiones corporativas, que se traducen en proposiciones no de ley técnicamente deficientes y ciertamente gratuitas.

Así, baste recordar la proposición no de ley sobre la regulación de la publicidad y el funcionamiento de las clínicas dentales en España, presentada el 15 de septiembre de 2016, la cual mezcla temas penales relacionados con fraudes, delitos de estafa, fiscales y de falsificación y blanqueo de dinero, obviamente ya regulados en el Código penal vigente, con cuestiones de índole laboral (propone "dictar instrucciones a la inspección de trabajo para que revise la existencia de "falsos autónomos" al servicio de dichas clínicas", como si la Inspección de trabajo no tuviera ya atribuido ese cometido) y termina por proponer la prohibición absoluta de cualquier tipo de comunicación comercial de tales actividades (sólo las de las clínicas dentales, paradójicamente) en medios no especializados y por restringir mucho más allá de lo razonable la financiación de semejantes tratamientos ${ }^{9}$. Al menos, la proposición no de ley relativa a mejorar y actualizar la regulación de la publicidad de los centros, establecimientos, y servicios sanitarios, presentada apenas unas semanas después por otro grupo político, reconoce ya la existencia de una regulación al respecto y no la reduce al ámbito de las clínicas dentales, lo que resultaba ciertamente reduccionista y absurdo, si bien, justo es reconocerlo, se limita a consideraciones generales y vacías de contenido que no aportan nada nuevo y concreto a la regulación ya existente, lo que vuelve a evidenciar

8. El presidente del Consejo de Dentistas de España critica, en relación con las actividades de las clínicas dentales cuestionadas, desde el papel de determinadas Universidades privadas y la Aneca, que facilitan el acceso a la profesión, al propio modelo de negocio de la franquicia o cuestiones relacionadas con el derecho societario (a su juicio, una deficiente ley de sociedades profesionales; sin olvidar temas propios del derecho penal (denuncia estafas y fraudes diversos) o laboral (la existencia de falsos autónomos o de conculcación de derechos básicos del trabajador) y el hecho de que las clínicas, en ocasiones, no dispongan de profesionales sanitarios al frente o, al menos, sin una presencia continuada obligatorio, lo cual, como es obvio, depende de la regulación administrativa de la propia actividad asistencial. Como se puede observar, el problema propiciado por las comunicaciones comerciales es uno más, y, probablemente, no el más importante. En Diario La Verdad, 10 de marzo de 2019, acceso el 9 de junio de 2020,

https://www.laverdad.es/murcia/colegio-paro-denunciar-20190310003103-ntvo.html

9. "1. Proceder a prohibir por ley, instando a llevar a cabo las modificaciones legales pertinentes en la normativa sanitaria, la publicidad en medios no especializados de las clínicas dentales. 2. Prohibir cualquier publicidad de instituciones sanitarias en cualquier medio, que incluya ofertas económicas, rebajas, premios, o cualquier otro tipo de atractivo económico. 3. Prohibir así mismo la obligatoriedad de firmar acuerdos de financiación para tratamientos no realizados, así como el pago por anticipado de los mismos. 4. Obligar a que sean transparentes y accesibles al público el nombre y número de colegiado de los especialistas en odontología que están al frente de dichas clínicas. 5. Dictar instrucciones a la inspección de trabajo para que revise la existencia de "falsos autónomos" al servicio de dichas clínicas. 6. Establecer un portal de transparencia en el que figuren obligatoriamente el tipo, número y porcentaje de tratamientos realizados en las clínicas dentales. 7. Obligatoriedad por parte de los colegios de Odontólogos de llevar un registro de reclamaciones realizadas en cada uno de ellos y que éste sea accesible al público general". Acceso el 11 de junio de 2020,

http://www.congreso.es/public_oficiales/L12/CONG/BOCG/D/BOCG-12-D-377.PDF 
que es únicamente fruto de una reacción a la presión corporativa existente ${ }^{10}$.

El pasado 28 de febrero de 2019, y continuando con los movimientos apuntados, se presenta en el Congreso una Proposición de Ley relativa a la publicidad de prestaciones y actividades sanitarias. Al margen de su escasa viabilidad parlamentaria, al menos a corto plazo, resulta sorprendente que apenas se incorpore novedad material alguna en relación con el acervo normativo existente ${ }^{11}$, y el hecho de que, si bien ha contado con el apoyo de muchos de los colegios profesionales implicados (a excepción, curiosamente, del Consejo general de Enfermería), ninguna asociación de consumidores o usuarios parece haber colaborado en la redacción del texto articulado, lo que vuelve a evidenciar que se han antepuesto los intereses económicos de un sector profesional afectado por una competencia especialmente agresiva, antes que la protección de la salud de colectivos desfavorecidos.

En definitiva, a la luz de lo expuesto, cabe plantearse si verdaderamente es necesario afrontar, ya no una nueva regulación de la publicidad de servicios sanitarios, sino una mera reforma de la misma. Parece que, independientemente de la necesidad de potenciar la labor inspectora, en muchos casos deficiente por la escasez de medios y efectivos, los principales problemas que se plantean por parte de los Colegios denunciantes, o bien se encuentran ya previstos en las normas vigentes, o bien pertenecen a ámbitos alejados del sector del marketing o las comunicaciones comerciales, como ya se ha expuesto. El hecho de que se invoque la defensa de particulares desfavorecidos para, en última instancia, proteger intereses corporativos, no ayuda a la causa planteada y, en todo caso, no justifica la reforma de un sector que, como se ha demostrado, se encuentra suficientemente regulado ${ }^{12}$, evidenciándose cuestiones

10. “1. Mejore, actualice y clarifique la regulación de la publicidad de centros, establecimientos y servicios sanitarios. 2. Garantice la seguridad de pacientes y usuarios, persiguiendo la publicidad engañosa y evitando los posibles prejuicios que puedan producirse. 3. Regule de forma detallada la inspección, el control, las responsabilidades y las sanciones que se deriven de la publicidad engañosa en estos centros, cualquiera que sea el régimen jurídico bajo el que presten sus servicios (franquicias, etc.). 4. Establezca los mecanismos de coordinación necesarios con las Comunidades Autónomas". Acceso el 21 de junio de 2020,

http://www.congreso.es/portal/page/portal/Congreso/Congreso/Organos/Comision?_piref73_7498063_73_1339256_1339256.

next_page $=/$ wc/servidorCGI\&oriIC $=$ S\&CMD=VERLST\&BASE=IW11\&PIECE $=I W 11 \& F M T=I N I T X D 1 S . f m t \& F O R M 1=$

INITXLGE.fmt\&QUERY=\%28I\%29.ACIN1.+\%26+325.NCOM.\&DOCS=41-41.

Como se puede observar, "lugares comunes" que no aportan nada sustancial a lo ya existente.

11. Acceso el 1 de julio de 2020,

http://www.pp.es/sites/default/files/documentos/19.02.28_pl_publicidad_sanitaria.pdf. Ni siquiera se aprovecha la propuesta para restringir de forma expresa, al estilo de lo que sucede en países como Bélgica, Alemania o Francia, la naturaleza mercantil de la actividad de prestación de servicios sanitarios, en un intento por reforzar la tradicional distinción entre la actividad empresarial y profesional, uno de cuyas claves es la exigencia de desempeño personal y la necesidad de acreditación académica para la segunda; en concreto, el Code de la santé publique francés, establece, en su art. R4127-19 que "La médecine ne doit pas être pratiquée comme un commerce", añadiendo que "Sont interdits tous procédés directs ou indirects de publicité et notamment tout aménagement ou signalisation donnant aux locaux une apparence commerciale". La incorporación de un precepto semejante a nuestro ordenamiento sí supondría el establecimiento de límites de cara al diseño de determinadas estrategias comerciales agresivas.

12. De hecho, más que una reforma de la regulación sustantiva de la publicidad, los colectivos de afectados demandarían antes una modificación de las normas procesales que permiten, por ejemplo, que, en el caso iDental, la Audiencia 
que se encuentran más cerca del ventajismo y oportunismo político que de la existencia de verdaderos vacíos legales, como se ha llegado a sostener.

\section{LA LUCHA CONTRA LAS PSEUDOCIENCIAS.}

El pasado 14 de noviembre de 2018, el Gobierno de España, a través de los antiguos Ministerios de Sanidad, Consumo y Bienestar Social y de Ciencia, Innovación y Universidades, presentó un Plan para la Protección de la Salud frente a las pseudoterapias. El referido Plan tenía como principal objetivo combatir las pseudociencias y sus efectos mediante diferentes actuaciones. Sobre la base del riesgo a la salud que tales pseudoterapias implican, bien por la promoción engañosa de sus inexistentes efectos terapéuticos, bien por provocar, directamente, nuevas dolencias o el agravamiento de las existentes al retrasar la aplicación de tratamientos realmente efectivos o minorar el efecto de estos, se proponían medidas concretas, entre las cuales estaba la modificación del Real Decreto 1907/1997, de 2 de agosto, sobre publicación y promoción comercial de productos, actividades o servicios con pretendida finalidad sanitaria, en los siguientes sentidos:

Acción 1. Incluir en la regulación los actos o encuentros que conlleven la publicación o promoción comercial de productos, actividades o servicios con pretendida finalidad sanitaria.

Acción 2. Incluir en la regulación la utilización de internet o redes sociales que conlleven la publicación o promoción comercial de productos, actividades o servicios con pretendida finalidad sanitaria.

Acción 3. Corresponsabilizar a los titulares, personas físicas y/o jurídicas, de los medios de comunicación y titulares de locales en la publicación o promoción comercial de productos, actividades o servicios con pretendida finalidad sanitaria y sin eficacia ni seguridad demostrada ${ }^{13}$.

Independientemente de la procedencia del plan en sí mismo, y del posible efecto positivo que podría haber supuesto la identificación pública y nominal de muchas de las pseudociencias que llevan años provocando serios problemas a aquellos pacientes que, en situaciones muchas veces desesperadas, se ven seducidos por la comercialización de semejantes prácticas ${ }^{14}$, aquí vamos a tratar de analizar el

Nacional haya denegado la personación como acusación particular en la causa de una plataforma que integra a más de 250 posibles damnificados, limitando aquéllas a un máximo de seis. Acceso el 12 de junio de 2020, https://confilegal. com/20190405-el-juez-de-idental-rechaza-la-personacion-de-una-plataforma-que-representa-a-250-afectados-por-elvolumen-de-la-causa/.

13. PLAN PARA LA PROTECCIÓN DE LA SALUD FRENTE A LAS PSEUDOTERAPIAS, noviembre de 2018, línea 2, objetivo 2. Acceso el 25 de junio de 2020, https://blogs.ua.es/aesppu/files/2019/05/PLAN-PROTECCI\%C3\%93N-SALUD-PSEUDOTERAPIAS.pdf.

14. Resulta curioso comprobar como los responsables políticos, a la hora de justificar la implementación de esta acción, se esfuerzan por recordar que, independientemente de la inclusión en la lista de las prácticas o sustancias consideradas pseudoterapias, la comercialización de las mismas no será prohibida, ni siquiera su dispensación en farmacias en caso de que ésta se viniera produciendo. Esta afirmación evidencia cierta inseguridad en el planteamiento general del problema, pues, por un lado, si se comprueba que, efectivamente, tales "tratamientos" resultan directa o indirectamente perjudi- 
alcance y procedencia de la modificación legislativa entonces propuesta, en un esfuerzo por aclarar si verdaderamente resultaba o no necesaria.

Comenzando por la primera acción propuesta, referida a la inclusión en la nueva regulación del Real Decreto aludido, de los "actos o encuentros que conlleven la publicación o promoción comercial de productos, actividades o servicios con pretendida finalidad sanitaria" no alcanzamos a entender qué norma o normas excluían tales actividades o, al menos, de qué eventual omisión normativa se deduce la existencia de una laguna a integrar con la modificación propuesta.

Así, tanto el art. 1 del Real Decreto, que se refiere al control de:

la publicidad y promoción comercial de los productos, materiales, sustancias, energías o métodos que se anuncian o presentan como útiles para el diagnóstico, prevención o tratamiento de enfermedades o desarrollos fisiológicos, adelgazamiento, modificación del estado físico o psicológico, restauración, corrección o modificación de funciones orgánicas u otras pretendidas finalidades sanitarias, para que se ajusten a criterios de veracidad en lo que atañe a la salud y para limitar todo aquello que pueda constituir un perjuicio para la misma.

Como el art. 4, que prohíbe "cualquier clase de publicidad o promoción directa o indirecta, masiva o individualizada, de productos, materiales, sustancias, energías o métodos con pretendida finalidad sanitaria” en determinados supuestos específicos, no sólo no excluyen en ningún caso que tales promociones tengan lugar en "actos o encuentros que conlleven la publicación o promoción comercial de productos, actividades o servicios con pretendida finalidad sanitaria” sino que, por el contrario, entendemos que no hace falta una especial interpretación de los preceptos transcritos para entenderlos incluidos bajo su respectivo ámbito de aplicación.

De igual forma, el empeño de la segunda acción propuesta por incluir, de forma expresa, la utilización de redes sociales o Internet como medios a través de los cuáles se difunden semejantes actividades

ciales para la salud (como la propia introducción del plan reconoce), los mismos habrían de ser prohibidos sin duda alguna y, por otro, si en relación con otras terapias, su problema radica en la realización de alegaciones terapéuticas no acreditadas pero desde la inocuidad absoluta del producto, entonces bastaría con garantizar la aplicación de las normas existentes a aquellas actuaciones concretas en las que se materialice esa conducta, sin "satanizar" las sustancias referidas con su inclusión en la "lista negra" confeccionada. Ver declaraciones y singular planteamiento en "Acupuntura, reiki, homeopatía, yoga, quiromasaje y shiatsu, entre las pseudociencias que investiga el Gobierno”, en Diario Sur, 1 de marzo de 2019, acceso el 29 de junio de 2020, https://www.diariosur.es/sociedad/sanidad-ciencia-realizan-listado-pseudoterapias-20190228123027-ntrc.html. Este planteamiento dubitativo ha generado, en ciertos colectivos, una sensación de fracaso en cuanto al proyecto acometido, considerando insuficiente el plan de concienciación y reclamando una regulación ad hoc, sin percatarse de que la misma ya existe y que muchas de sus quejas nada tienen que ver con la existencia de una laguna legal, sino, como ellos mismos reconocen en sus manifestaciones, con la "pasividad" de la Administración o con la dificultad que implica controlar los nuevos canales de comercialización a través de Internet. Lorenzo Ramírez, "El Gobierno fracasa en su lucha contra el fraude sanitario de los falsos "productos milagro"”, en 65YMÄS.COM, 30 de marzo de 2019, acceso el 30 de junio de 2020, https://www.65ymas.com/sociedad/el-gobierno-fracasa-en-su-luchacontra-el-fraude-sanitario-de-los-falsos-productos-milagro_2008_102.html. 
promocionales tampoco resulta, más allá del mero ánimo enfatizador o divulgativo (el cual, creemos, no debiera de materializarse en una norma jurídica), procedente, pues, como en el caso recién apuntado, nada hace pensar que tal ámbito se encuentre exento del control del Real Decreto cuya modificación se propone. Cuestión muy distinta son los tradicionales problemas de legislación aplicable y jurisdicción competente que, en muchas ocasiones, hacen realmente difícil el control de prácticas promocionales que tengan lugar en ese escenario, pero, en cualquier caso, esas incidencias no se van a resolver con la modificación legislativa propuesta, la cual resulta a todas luces gratuita ${ }^{15}$.

En cuanto a la tercera acción, que propone la extensión de la responsabilidad a los medios de comunicación y "titulares" de locales donde se desarrollen las actividades objeto de control, aquí sí se realiza una propuesta que, al menos en parte, supone una importante novedad respecto de lo establecido en la legislación vigente.

Así, tal reforma consagraría una línea jurisprudencial ya apuntada por la Sentencia de la Audiencia Provincial de Madrid de 30 de diciembre de $2009^{16}$, la cual condenaba en calidad de cooperador necesario a la editora de la revista "Diez Minutos" por haber publicado un anuncio del producto "Programa Integral Reforzado (CIR 2000)", declarado desleal por realizar alegaciones adelgazantes prohibidas por el Real Decreto 1907/1996, de 2 de agosto, sobre publicidad y promoción comercial de productos, actividades o servicios con pretendida finalidad sanitaria.

Sin embargo, e independientemente de esta modificación, que sí resultaría procedente, la "corres-

15. La innecesaridad de las modificaciones propuestas aún se hace más evidente si, al alcance del Real Decreto analizado, se suman el resto de normas generales que disciplinan la actividad concurrencial, la cual, no puede olvidarse, se materializa fundamentalmente a través de actuaciones publicitarias. Así, la LCD, en sus artículos 5 y 7 y, de forma muy especial, en el art. 23.3, proscriben de forma clara las comunicaciones comerciales que incurran en actos de engaño, bien por acción, bien por omisión, con alusión expresa a aquellas prácticas comerciales con consumidores que proclamen "falsamente, que un bien o servicio puede curar enfermedades, disfunciones o malformaciones", precepto que resultaría plenamente aplicable al ámbito de las pseudoterapias cuyo control se pretende reforzar.

16. La sentencia, que declara la ilegalidad de la publicidad denunciada tanto por su vulneración de la norma sectorial específica como de las generales establecidas en la LCD, justifica de esta forma la viabilidad de la acción contra la revista: "a la vista de los amplios términos en que aparece configurada la legitimación pasiva en el artículo 20.1 de la Ley de Competencia Desleal, a tenor del cual "Las acciones previstas en el artículo 18 podrán ejercitarse contra cualquier persona que (.) haya cooperado en su realización (del acto de competencia desleal)", lo cual implica que la demanda puede dirigirse contra cuantos brindan cooperación a la realización de un acto de competencia desleal facilitando con sus medios propios la realización del acto en cuestión, y sin cuya cooperación el meritado acto no habría tenido lugar, con ciertas matizaciones en cuanto a la acción de resarcimiento (al exigirse, artículo $18.5^{\mathrm{a}}$ de la ley especial, que haya mediado dolo o culpa del agente ) y la de enriquecimiento injusto (artículo 20.1 in fine: "No obstante, la acción de enriquecimiento injusto sólo podrá dirigirse contra el beneficiario del enriquecimiento"). En esta categoría entrarían (así lo considera también reputada doctrina expresamente invocada por la parte apelante) los medios de comunicación a través de los cuales se difunda publicidad ilícita o engañosa constitutiva de un acto de competencia desleal, como es el caso, independientemente de su ajenidad al contenido del anuncio publicitado o la finalidad perseguida por el anunciante, y sin perjuicio de las matizaciones procedentes por razón de la clase de acción ejercitada en el sentido anteriormente apuntado". SAP Madrid (sección 28) núm. 318/2009 de 30 diciembre (JUR 2010\92351). 
ponsabilización" a los titulares de locales en donde se desarrollen las actividades promocionales resulta absolutamente excesiva. Una cosa es la responsabilidad editorial del titular del medio de comunicación en donde se publica el anuncio, que resulta fuera de cualquier discusión, dado el necesario control que el editor ha de tener sobre toda aquella información que se exterioriza a través de su medio, y otra, muy distinta, la responsabilidad del "titular" del local en donde tiene lugar la eventual promoción de la pseudociencia. Si bien el editor tiene, en todo caso, acceso previo y conocimiento del contenido de aquello que va a ser objeto de difusión en su medio, y, por lo tanto, capacidad preventiva para evitar su publicación, la persona física o jurídica con título habilitante para el uso o disposición del local (pues entendemos que este es el sentido en el que se utiliza el término "titular") desconocerá, en muchas ocasiones, la concreta actividad que va a tener lugar en el espacio físico que cede, independientemente del negocio jurídico que de soporte a ese uso, y, por lo tanto, carecerá de capacidad de reacción al respecto. La corresponsabilización propuesta no tiene precedentes penales, civiles o administrativos en ningún ámbito cercano al expuesto, y su posible implementación generaría una inseguridad jurídica tremendamente perjudicial para el tráfico económico, sin perjuicio de su eventual ilegalidad.

Y si esta propuesta resulta ciertamente extravagante desde un punto de vista jurídico, tampoco parece muy sensata la apostilla última que culmina el precepto, pues la exigencia de que los productos o servicios promocionados no cuenten con eficacia o seguridad demostrada, no hace sino sintetizar y simplificar en exceso lo referido de forma detallada en el art. 4.1.16 del Real Decreto vigente, que ya prohibía la publicidad o promoción, directa o indirecta, de productos, materiales, sustancias, etc. "que atribuyan efectos preventivos o terapéuticos específicos que no estén respaldados por suficientes pruebas técnicas o científicas acreditadas y expresamente reconocidas por la Administración sanitaria del Estado ${ }^{17 ”}$.

El Plan que ahora se analiza finaliza sus propuestas de modificación legislativa con dos líneas de actuación más, centrada la primera en el desarrollo reglamentario de lo establecido en el artículo 51.2, relacionado con los medicamentos de plantas medicinales, del Real Decreto Legislativo 1/2015, de 24 de julio, por el que se aprueba el texto refundido de la Ley de garantías y uso racional de los medicamentos y productos sanitarios, y orientada la segunda a la modificación del Real Decreto 1416/1994,

17. Paradójicamente, en USA, la Federal Trade Comisión se pronunció en noviembre de 2016 respecto de los productos homeopáticos en el siguiente sentido: "The FTC has long recognized that marketing claims may include additional explanatory information to prevent the claims from being misleading. Accordingly, it recognizes that an OTC homeopathic drug claim that is not substantiated by competent and reliable scientific evidence might not be deceptive if the advertisement or label where it appears effectively communicates that: 1) there is no scientific evidence that the product works; and 2) the product's claims are based only on theories of homeopathy from the 1700s that are not accepted by most modern medical experts" Lo que, en principio, pudiera parecer un avance no es más que una legitimación que permite a estos productos, simplemente incluyendo las advertencias exigidas, realizar alegaciones terapéuticas que en ningún caso han sido contrastadas científicamente. Acceso el 2 de julio de 2020, https://sciencebasedmedicine.org/ftc-homeopathy-win/. Sin duda, la solución adoptada por la norma española es mucho más respetuosa con el derecho a una información veraz que hay que garantizar a todo consumidor, especialmente en un ámbito como el sanitario. 
de 25 de junio, por el que se regula la publicidad de medicamentos de uso humano y de los productos sanitarios con objeto de reforzar el régimen de sanciones relativas a la publicidad de un medicamento que no haya obtenido la correspondiente autorización de comercialización.

En relación con estas dos últimas propuestas, cabe diferenciar la indudable procedencia de establecer, en aras a incrementar la seguridad de posibles usuarios, una lista de plantas cuya venta al público estará restringida o prohibida por razón de su toxicidad, tal y como dispone el real Decreto Legislativo citado, de la más que dudosa necesidad de reformar el régimen sancionador del Real Decreto de 1994, especialmente porque el ámbito de aplicación de tal norma poco tiene qué ver con la materia que ahora se intenta controlar, la cual, conviene no olvidarse, entiende la pseudoterapia como aquella "sustancia, producto, actividad o servicio con pretendida finalidad sanitaria que no tenga soporte en el conocimiento científico ni evidencia científica que avale su eficacia y su seguridad", y, por tanto, algo absolutamente alejado de lo que se concibe normativamente como medicamento, esté éste autorizado o no.

En definitivo, el escaso rigor con el que, desde un punto de vista jurídico, se plantean las acciones a adoptar en sede de reforma de la legislación publicitaria vigente, así como la existencia de normas que afrontan ya con éxito en el panorama nacional y europeo ${ }^{18}$ el control de prácticas publicitarias engañosas en semejante sector ${ }^{19}$, y, por último, el riesgo que se asume con la mera realización de una lista que, de forma apriorística, determine qué técnicas o tratamientos han de ser considerados o no como pseudoterapias $^{20}$, hace que, cuando menos, la necesidad existente de proceder a una reforma urgente

18. Incluso existe una norma específica que regula, de forma muy garantista, la presencia de "alegaciones salud" en los alimentos, como es el Reglamento (CE) no 1924/2006 relativo a las declaraciones nutricionales y de propiedades saludables en los alimentos.

19. Casos como la retirada de la publicidad de un aceite del que se predicaban, entre otras, propiedades farmacéuticas, antiinflamatorias y anticancerígenas, o la sanción impuesta a un individuo que aseguraba curar el autismo con lejía demuestran que la Administración tiene facultades para luchar contra semejantes prácticas. "Retiran la publicidad que otorgaba propiedades milagrosas al aceite Fergus”, en Nuevatribuna.es, 26 de marzo de 2018, acceso el 1 de julio de 2020, https://www.nuevatribuna.es/articulo/consumo/retiran-publicidad-otorgaba-propiedades-milagrosas-aceitefergus/20180326181223150202.html; "Nueva multa al «curandero» Pàmies: 600.000 euros por promocionar la lejía para combatir el autismo", en Diario ABC, 16 de octubre de 2018, acceso el 3 de julio de 2020,

https://www.abc.es/espana/catalunya/abci-nueva-multa-curandero-pamies-600000-euros-promocionar-lejia-

para-combatir-autismo-201810261505_noticia.html. No olvidemos que, aparte de las actuaciones administrativas reseñadas, tales actuaciones bien podrían tener repercusiones penales, como ha sucedido en Francia recientemente con la condena a 2 años de prisión y $30.000 €$ de multa que el Tribunal penal de Montpellier, en sentencia de 4 de noviembre de 2015, ha impuesto por publicidad engañosa al fundador de la "biología total", tras constatar el fallecimiento de un paciente de cáncer que había decidido abandonar todo tratamiento siguiendo los postulados de semejante teoría. Acceso el 7 de julio de 2020, https://france3-regions.francetvinfo.fr/occitanie/herault/montpellier-metropole/montpellier/ fondateur-biologie-totale-condamne-2-ans-ferme-montpellier-844921.html. Conviene recordar, a este respecto, que el Código Penal español cuenta con un precepto específico aplicable a tales supuestos, cual es el art. 282, que señala que "serán castigados con la pena de prisión de seis meses a un año o multa de 12 a 24 meses los fabricantes o comerciantes que, en sus ofertas o publicidad de productos o servicios, hagan alegaciones falsas o manifiesten características inciertas sobre los mismos, de modo que puedan causar un perjuicio grave y manifiesto a los consumidores, sin perjuicio de la pena que corresponda aplicar por la comisión de otros delitos".

20. La cuestión no es, ni mucho menos, pacífica, ni siquiera desde el punto de vista político, como muestran las recientes declaraciones del Consejero de Sanidad de la Comunidad de Madrid, que se muestra contrario a incluir la homeopatía como pseudoterapia, aludiendo incluso a evidencias académicas y científicas en contra de tal declaración. "El consejero 
del acervo legislativo existente sea más que cuestionable, especialmente si, como se va a exponer en el próximo epígrafe, existen otros ámbitos que reclaman, de manera mucho más acuciante, la atención del legislador ${ }^{21}$.

Desde luego, y a diferencia de otros sistemas jurídicos, en España la comunicación publicitaria de propiedades pretendidamente terapéuticas de sustancias o productos no considerados medicamentos, se encuentra ciertamente controlada ${ }^{22}$.

\section{LA ADICCIÓN AL JUEGO Y SU INSUFICIENTE REGULACIÓN EN SEDE PUBLICITARIA}

\subsection{Contexto actual y régimen jurídico}

Si bien pudiera parecer que la regulación de la publicidad del juego o de las apuestas se encuentra alejada del ámbito de la protección de la salud en el que se encuadra este trabajo, al apreciarse, al menos en un primer momento, consecuencias más relacionadas con los intereses económicos que con la salud de los posibles afectados, lo cierto es que el juego patológico está considerado, ya desde 1980, como entidad nosológica de salud mental, habiendo sido expresamente incluido como trastorno en el Manual Diagnóstico y Estadístico de los Trastornos Mentales ${ }^{23}$. Por lo tanto, la ludopatía como patología, y de forma muy especial su posible incidencia en relación con sectores poblacionales desprotegidos o

de Sanidad de Madrid rechaza declarar a la homeopatía como pseudoterapia”, en Diario El Boletín, 25 de marzo de 2019, acceso el 5 de julio de 2020,

https://www.elboletin.com/noticia/172350/sanidad/el-consejero-de-sanidad-de-madrid-rechaza-declarar-a-la-

homeopatia-como-pseudoterapia.html. Lo cierto es que, en casos que pudieran resultar controvertidos, quizás fuera mejor permitir a los tribunales que analizaran el caso concreto, sin listas previas que predeterminen, de forma absoluta, la naturaleza de las prácticas discutidas.

21. No hay que olvidar que, en este ámbito, como en el de la publicidad de clínicas dentales estudiado en el segundo epígrafe de este trabajo, los lobbies más poderosos están posicionados a favor de la acción política ahora cuestionada. Sin caer en teorías de la conspiración (a modo de anécdota, acceso el 8 de julio de 2020,

http://bles.com/mundo/noticias-google-publicidad-medicina.html), lo cierto es que el lobby de los medicamentos es uno de los más influyentes en la actualidad y, sin duda, sería también uno de los principales beneficiados por la regulación ahora propuesta.

22. Ver nota 18, por contraposición. Incluso los sistemas de autorregulación publicitaria se han mostrado ciertamente contundentes a la hora de atajar comunicaciones comerciales en las que se utilizan, sin suficiente contraste científico, alegaciones de tipo terapéutico o preventivo. Como muestra, baste este extracto de la resolución del Jurado de la Publicidad, de 5 de septiembre de 2007, en relación con un anuncio de un agua mineral: "una vez analizado el anuncio reclamado, el Jurado constató que los datos que se reflejan en la publicidad no se corresponden de manera fidedigna con los recogidos en el informe de la OMS en el que la propia publicidad dice apoyarse. Además, la Sección entendió que en este caso, las alegaciones utilizadas por la reclamada en su publicidad debían ser consideradas alegaciones terapéuticas, preventivas o curativas prohibidas por el precepto antes referido, de modo que la publicidad reclamada infringe el Real Decreto 1907/1996, que prohíbe que se inserten determinadas menciones a través de las cuales se atribuyan propiedades sanitarias, esto es, propiedades preventivas, curativas, terapéuticas o adelgazantes en la publicidad de cualesquiera productos que, como es el caso, no merezcan la consideración legal de medicamentos".

23. Acceso el 20 de julio de 2020, http://www.cop.es/colegiados/t-00932/juego.html. 
vulnerables, como pueden ser los menores de edad, debería de contar con una singular atención por parte del legislador, esforzándose éste por articular un conjunto de medidas tuitivas que resultasen ciertamente efectivas.

El panorama actual muestra, además, circunstancias que agravan extraordinariamente el problema. Por un lado, la popularización de las actividades de juego y apuestas a través de Internet, con lo que eso supone de accesibilidad e inmediatez en la asunción de la decisión de "compra" del producto ofertado, incrementándose asimismo los problemas de control de cara a garantizar el uso adecuado de aplicaciones y software; por otro lado, el acoso constante a que se ve sometido el ciudadano en forma de comunicaciones comerciales especialmente invasivas y agresivas, vinculadas además a actividades deportivas o culturales y plagadas de "testimoniales" interesados de personajes célebres en sus respectivos ámbitos profesionales. Y, por si los aspectos intrínsecos de la actividad y su desarrollo no fueran singularmente complejos de cara a articular una regulación adecuada que minimice los problemas ocasionados, los intereses económicos en torno al sector se muestran cada día más influyentes, excediendo de los ínsitos a la propia industria del juego, y afectando a sectores ajenos que, de una u otra forma, dependen en buena medida de los ingresos obtenidos como vehículos publicitarios de semejante actividad económica ${ }^{24}$.

En este contexto, es especialmente delicada la situación en que se encuentran los menores de edad, los cuales, por razones obvias, no cuentan aún con la suficiente capacidad de raciocinio para afrontar con la debida información y sosiego la decisión de participar en una actividad del riesgo potencial que presenta, en términos generales, el juego ${ }^{25}$. El hecho de que, independientemente de la prohibición legal existente ${ }^{26}$, el acceso de este grupo poblacional a, por ejemplo, apuestas online, sea muy difícilmente evitable desde el punto de vista técnico; la estrecha vinculación existente entre actividades extraordinariamente populares entre los jóvenes, como son las relacionadas con el deporte profesional, y

24. Así, tras la aprobación de la norma italiana que prohíbe de forma terminante la publicidad del juego en el país transalpino, los equipos del Calcio se quejaron amargamente de perder una de sus fuentes principales de ingresos, ya que la mitad de los equipos de la "Serie A" se encontraban patrocinados por casas de apuestas, percibiéndose, aproximadamente, unos 120 millones de euros al año por ese u otros conceptos relacionados con la promoción del juego online, principalmente. La propia asociación denunció que la nueva regulación les situaba en una posición de desventaja competitiva respecto de otros clubes de Europa.

25. Plantean también problemas singulares para los menores las cada vez más frecuentes Loot Boxes o cajas de botín en videojuegos, las cuales no se encuentran habitualmente bajo el ámbito de aplicación de las normas que regulan el juego a pesar de ser, conceptualmente, actos en los que se arriesga una cantidad de dinero o especie equivalente a cambio de la posibilidad de obtener un benéfico incierto o aleatorio, con lo que bien podrían integrarse en semejante ámbito. Han sido ya tres países los que se han planteado esta consideración, obteniendo resultados diferentes en función de sus distintas regulaciones, pero lo cierto es que, en cualquier caso, se hace necesario articular un régimen concreto que discipline tales prácticas. Darío López Rincón, "Gambling o juego regulado", en ELDERECHO.COM LEFEBVRE, acceso el 14 de julio de 2020, https://elderecho.com/gambling-o-juego-regulado.

26. El artículo 6.2.a de la Ley 13/2011, de 27 de mayo, de regulación del juego, prohíbe la participación de los menores de edad en los juegos que se encuentran bajo el ámbito de aplicación de esta norma, si bien tal prohibición resulta, como es obvio, difícilmente aplicable en el denominado juego online. 
el submundo de las apuestas deportivas, convirtiendo esta práctica en una actividad de moda entre los adolescentes; y el diseño de estrategias promocionales y de comercialización dirigidas especialmente a este grupo de riesgo, como son los anuncios de casas de apuestas deportivas protagonizados por ídolos del fútbol o apps diseñadas para fidelizar a futuro a menores de edad, bajo la añagaza de jugar, en tales aplicaciones, con monedas virtuales. Todas estas circunstancias, entre muchas otras, están generando un aumento de las ludopatías a edades cada vez más precoces y justificarían sobradamente una decidida actuación del poder legislativo de cara a eliminar o, al menos, restringir semejantes actuaciones ${ }^{27}$.

El régimen jurídico actual no protege suficientemente los intereses de los potenciales afectados. Así, la Ley 13/2011, de 27 de mayo, de regulación del juego, al margen de la declaración programática que consta en su art. 1, referente a la prevención de las conductas adictivas y la protección de los derechos de los menores, entre otros objetivos, no concreta luego con medidas aplicables tales encomiables propósitos. A pesar de que la norma tiene como objeto "en particular" la regulación de las actividades de juego que se desarrollen a través de "canales electrónicos, informáticos, telemáticos e interactivos, en la que los medios presenciales deberán tener un carácter accesorio" (art. 1) y que las actividades de publicidad, promoción y patrocinio relativas a tales actividades se encuentran también bajo el ámbito de aplicación de la norma (art. 2.1 in fine), por lo que pudiera parecer, prima facie, que la Ley tiene como objeto principal hacer frente a los problemas que están originando en la actualidad esas actividades, lo cierto es que apenas una referencia al deber de evitar el acceso de los menores al juego en un futuro desarrollo reglamentario (art. 5.4), la prohibición subjetiva establecida en el art. 6.1.a o, ya en sede de RSC y prevención, la necesidad de informar de acuerdo con la naturaleza y medios utilizados en cada juego de la prohibición de participar a los menores de edad (art. 8.1.c) -cuya inobservancia se sanciona como infracción leve en el art. 41.d-, constan en la Ley como preceptos que dedican especial atención a este grupo particularmente afectado.

En cuanto a sectores como el de las apuestas deportivas online, que implica, por su tremenda popularidad, un especial riesgo para los menores, el mismo se encuentra regulado en la Orden HAP/1369/2014, de 25 de julio, por la que se aprueba la reglamentación básica de las apuestas cruzadas, y se modifican distintas órdenes ministeriales por las que se aprueba la reglamentación básica de determinados juegos. Un precepto de esta norma que, de alguna forma, atiende a la protección específica de los intereses de nińos y adolescentes es el art. 9.1.b, que, entre los criterios a valorar para autorizar la realización de publicidad, patrocinio o promoción de la actividad regulada, dispone "que se asegure que la actividad publicitaria sea socialmente responsable, prestando la debida atención a la protección de menores y otros grupos particularmente vulnerables. Así, en el caso de los menores, deberá evitarse que la publicidad vaya dirigida a ellos, o que sea especialmente atractiva para niños y jóvenes menores

27. Sobre el tema, ver Alejandra Hernández Ruiz," La protección al consumidor en las webs de juego online de los operadores con licencia en España”, en Adicciones, vol. 32, nº. 3, (2020): 216-224 y Pablo García Ru Pablo García Ruiz, Pilar Buil y María José Solé Moratilla, "Consumo de riesgo: menores y juegos de azar online. El problema del "juego responsable”, en Política y Sociedad, Vol.53, №2 (2016): 551-575. 
de edad, o que éstos tengan un papel significativo en la concreta actividad promocional". Obsérvese que, si bien las declaraciones generales realizadas son, sin duda, positivas, la ausencia de concreción de las mismas permite que, en la práctica, bien sean obviadas, bien, directamente, la industria no las asuma como aplicables a sus prácticas. Por poner sólo algún ejemplo, tanto el patrocinio de equipos de futbol por parte de diferentes casas de apuestas deportivas online (con sus logos omnipresentes en las equipaciones que tales equipos comercializan) como el hecho de que éstas sean publicitadas por deportistas que son ídolos de los menores de edad convierten a estos en un indudable target de las actividades promocionadas, sin que, paradójicamente, se entienda vulnerado el artículo recién reproducido. Es obvio que, como en otros ámbitos que también generan adicciones, como el consumo de alcohol y el tabaco, un esfuerzo de concreción hubiera facilitado enormemente la aplicación de la norma.

Asimismo, el art. 9.1.c establece que:

En el caso de su emisión por medios de comunicación audiovisuales, deberá, además, respetar las disposiciones aplicables sobre comunicaciones comerciales y de autopromoción contenidas en la Ley 7/2010, de 31 de marzo, General de la Comunicación Audiovisual, y, en particular las previsiones del artículo 7 sobre los derechos del menor. Igualmente, se prestará especial atención al horario de emisión de la publicidad de la actividad de juego y se tendrá en cuenta la calificación por edades del programa junto al que se emite o se inserte la misma.

A este respecto, hay que remitirse, como es evidente, a lo dispuesto en la Ley 7/2010, de 31 de marzo, General de la Comunicación Audiovisual, cuyo artículo 7.2, en sus párrafos primero y segundo, dispone lo siguiente:

Está prohibida la emisión de contenidos audiovisuales que puedan perjudicar seriamente el desarrollo físico, mental o moral de los menores, y, en particular, la de aquellos programas que incluyan escenas de pornografía, maltrato, violencia de género o violencia gratuita.

Aquellos otros contenidos que puedan resultar perjudiciales para el desarrollo físico, mental o moral de los menores solo podrán emitirse en abierto entre las 22 y las 6 horas, debiendo ir siempre precedidos por un aviso acústico y visual, según los criterios que fije la autoridad audiovisual competente. El indicador visual deberá mantenerse a lo largo de todo el programa en el que se incluyan dichos contenidos. Cuando este tipo de contenidos se emita mediante un sistema de acceso condicional, los prestadores del servicio de comunicación audiovisual deberán incorporar sistemas de control parental.

Pues bien, de lo referido en la norma general, se concluye, primero, que la actividad del juego no resulta prohibida de cara a su emisión por medios audiovisuales, por no ser una de las particularmente consideradas como dañina para el desarrollo del menor de edad. Si acaso, al entenderse como "otro contenido" que pudiera resultar perjudicial en tal sentido, pudiera someterse a una restricción horaria como la apuntada en el segundo párrafo del precepto. Sin embargo, tanto el hecho de que la definición de comunicación comercial que da la Ley, a pesar de comprender el carácter indirecto de la misma, 
exija la contraprestación económica al programa (presupuesto que no se da, por ejemplo, en los partidos de fútbol que exhiben patrocinios de casas de apuestas durante el desarrollo del juego), como la circunstancia de que muchos de los espectáculos referidos se emitan "en cerrado", limitándose entonces la norma a exigir un sistema de control parental, dejaría, incluso en el caso de que la norma pudiese servir para constreñir al horario establecido la publicidad "tradicional" - cosa que hasta el momento no sucede-, muchas de las actuaciones promocionales potencialmente perjudiciales para los menores fuera del ámbito de control de la norma. De hecho, tampoco el art. 7.2, en su párrafo séptimo, solucionaría problema alguno en el sentido referido, al aludir únicamente a "programas dedicados a juegos de azar y apuestas", y no a la publicidad de las mismas, por lo que la restrictiva banda horaria prevista tampoco sería de aplicación.

A la luz de lo expuesto, no parece descabellado pensar que una regulación que concretase más los límites y restricciones a aplicar a las comunicaciones comerciales que tengan por objeto la actividad del juego y que pudieran resultar accesibles a menores de edad hubiera resultado, sin duda, procedente.

\subsection{Derecho comparado}

En Europa, ya se han materializado movimientos en este sentido, algunos de ellos especialmente contundentes. Así, el art. 9.1 del Decreto-Legge de 12 de julio de 2018, conocido popularmente como Decreto "per la dignita", establece, como medida principal de lucha contra la ludopatía, lo siguiente:

Ai fini del rafforzamento della tutela del consumatore e per un piu' efficace contrasto alla ludopatia (...) e' vietata qualsiasi forma di pubblicita', anche indiretta, relativa a giochi o scommesse con vincite di denaro, comunque effettuata e su qualunque mezzo, incluse le manifestazioni sportive, culturali o artistiche, le trasmissioni televisive o radiofoniche, la stampa quotidiana e periodica, le pubblicazioni in genere, le affissioni e internet. Dal $1^{\circ}$ gennaio 2019 il divieto di cui al presente comma si applica anche alle sponsorizzazioni di eventi, attivita', manifestazioni, programmi, prodotti o servizi e a tutte le altre forme di comunicazione di contenuto promozionale, comprese le citazioni visive e acustiche e la sovraimpressione del nome, marchio, simboli, attivita' o prodotti la cui pubblicita', ai sensi del presente articolo, e’ vietata.

Obsérvese como la prohibición establecida resulta total y absoluta, independientemente del medio a través del que se difunda la comunicación, de la naturaleza concreta del juego promocionado, de si es publicidad directa, indirecta o patrocinio o esponsorización, y al margen del público objetivo de la misma.

Además, la norma concreta ya, en su art. 9.2, tanto los posibles sujetos responsables como la cuantía de la sanción a aplicar, de indudable efecto disuasorio, como se puede observar:

(...) l'inosservanza delle disposizioni di cui al comma 1, comporta a carico del committente, del proprietario del mezzo o del sito di diffusione o di destinazione e dell'organizzatore della manifes- 
tazione, evento o attivita', ai sensi della legge 24 novembre 1981, n. 689, l'applicazione di una sanzione amministrativa pecuniaria commisurata nella misura del $5 \%$ del valore della sponsorizzazione o della pubblicita' e in ogni caso non inferiore, per ogni violazione, a euro 50.000.

Probablemente esta no sea una referencia válida a la hora de adoptar una medida semejante para España. La radicalidad de la decisión legislativa tomada se encuentra trufada de un cierto populismo, y la ausencia absoluta de matices la convierte en una norma difícilmente exportable ${ }^{28}$.

Sin embargo, recientemente se ha aprobado una reforma de la publicidad del juego y gambling por Internet en Bélgica, la cual, como se va a comprobar a continuación, sí puede constituir un buen ejemplo a la hora de plantear una posible propuesta de modificación de la norma española. La nueva norma belga, materializada en el Arrêté royal relatif aux modalités d'exploitation des jeux de hasard et des paris exploités au moyen des instruments de la société de l'information, de 25 de octubre de 2018, además de disponer una serie de prevenciones generales en las que también se evidencia la preocupación por los colectivos especialmente vulnerables, bien por razón de edad, bien por razón de situación económica ${ }^{29}$, establece medidas concretas en los siguientes ámbitos:

- Limitación muy severa de la publicidad del juego online:

Les titulaires de licence de classe $\mathrm{A}+\mathrm{ou} \mathrm{B}+$ peuvent faire la promotion des jeux de hasard qu'ils exploitent au moyen des instruments de la société de l'information uniquement

28. De hecho, en Italia la norma ha generado una gran controversia, sosteniendo las empresas del sector que las restricciones impuestas de forma sobrevenida contravenían frontalmente el propio contenido de las licencias que tenían otorgadas.

29. Art. 2.\$1. "Les publicités en faveur des jeux de hasard et des paris exploités par les titulaires d'une licence de classe $\mathrm{A}+, \mathrm{B}+$ ou $\mathrm{F} 1+$ via les instruments de la société de l'information ne peuvent pas:

$1^{\circ}$ exagérer les chances de gain;

$2^{\circ}$ créer ou entretenir une dépendance au jeu ou inciter à jouer abusivement;

$3^{\circ}$ mentionner des données relatives aux gains ou aux chances de gains qui ne soient pas vérifiables ou conformes aux taux de retour au joueur du jeu concerné;

$4^{\circ}$ suggérer que le fait de gagner dépend uniquement de la connaissance du jeu;

$5^{\circ}$ faire l'éloge des personnes qui jouent ou critiquer celles qui ne jouent pas;

$6^{\circ}$ faire pression sur une personne si elle ne souhaite pas participer au jeu;

$7^{\circ}$ suggérer que tous les participants vont gagner des sommes importantes;

$8^{\circ}$ insinuer que le jeu est une solution aux problèmes financiers et personnels;

$9^{\circ}$ suggérer que le jeu constitue une alternative au travail et à l'épargne;

$10^{\circ}$ sous-entendre que jouer est une manière de rembourser les factures et dettes;

$11^{\circ}$ jouer sur la vulnérabilité des personnes éprouvant des difficultés financières ou exploiter leurs difficultés financières (...)

$14^{\circ}$ promouvoir ou s'associer à des publicités offrant des prêts qui peuvent être obtenus dans le but de jouer (...)”.

También resulta especialmente interesante la alusión al tamaño mínimo que la referencia a la edad requerida para participar en la actividad, o la preceptiva advertencia de "Jouez avec modération!" (que hasta entonces era voluntaria y no obligatoria) han de tener: "La taille des lettres d’un message écrit visé au précédent alinéa doit correspondre à au moins $4 \%$ de la taille de l'espace publicitaire et a une valeur minimum de 7 points sans être inférieure au quart de la taille des caractères les plus grands utilisés dans la publicité” (Art. 2.\$2, segundo párrafo). 
sur le site Internet sur lequel l'exploitation de ces jeux est autorisée ou par le biais de publicités personnalisées au sens du Livre VI ou du Livre XII du Code de droit économique. Les titulaires d'une licence de classe $\mathrm{A}+\mathrm{ou} \mathrm{B}+$ doivent veiller à n'adresser aucune publicité personnalisée aux personnes auxquelles l'accès aux jeux de hasard est interdit ou refusé en vertu de l'article 54 de la loi du 7 mai 1999 sur les jeux de hasard, les paris, les établissements de jeux de hasard et la protection des joueurs (art. 1er).

- Retransmisiones de eventos deportivos en directo: “(...) aucune publicité ne sera diffusée $1^{\circ}$ durant le reportage en direct de compétitions sportives, à savoir pendant la période qui va du commencement effectif de la compétition sportive en question diffusée en direct jusqu’à la fin effective de cette compétition sportive, quel que soit le média utilisé pour émettre le reportage en direct" (art. $3 \$ 1 \mathrm{er} .1^{\circ}$ ).

- Horarios protegidos para menores:

(...) aucune publicité ne sera diffusée (...) $2^{\circ}$ durant la période de quinze minutes qui précède le début et la période de quinze minutes qui suit la fin de programmes qui s’ adressent spécifiquement à des enfants et des mineurs.

Pour les titulaires d'une licence de classe $\mathrm{A}+\mathrm{B}+$ et $\mathrm{F} 1+$, aucune publicité pour des paris sportifs en ligne ne sera diffusée avant 20 heures, sauf en cas de diffusion de programmes sportifs $\left(\operatorname{art} 3 \$ 1 \mathrm{er} .2^{\circ}\right)$.

- Utilización de menores en la publicidad ${ }^{30}$ y product placement:

Les publicités pour les paris exploités au moyen des instruments de la société de l' information par les titulaires d'une licence de classe F1+ ne peuvent pas:

$1^{\circ}$ encourager les mineurs d'âge à jouer ou faire croire que les mineurs d'âge peuvent jouer, ni cibler les mineurs d'âge ou mettre en scène dans des publicités des personnes qui sont ou paraissent être des mineurs d'âge jouant à un paris;

$2^{\circ}$ inciter les mineurs à persuader leurs parents ou d'autres personnes à participer aux paris faisant l'objet de cette publicité;

30. Es de reseñar que la edad de referencia en Bélgica para participar en actividades de juego son 21 años, lo que se refleja en las normas que limitan determinadas prácticas publicitarias: "Les publicités, communications ou actions promotionnelles en faveur des jeux de hasard exploités par les titulaires d'une licence de classe A+ ou B+ via les instruments de la société de l'information ne peuvent pas:

$1^{\circ}$ encourager les personnes âgées de moins de 21 ans à jouer ou leur faire croire qu’elles sont autorisées à jouer, cibler ces personnes ou mettre en scène dans des publicités des personnes qui sont ou paraissent âgées de moins de 21 ans en train de prendre part à un jeu de hasard;

$2^{\circ}$ inciter les personnes âgées de moins de 21 ans à persuader leurs parents ou d'autres personnes à participer aux jeux de hasard faisant l'objet de cette publicité ( $\operatorname{art.} 3 \$ 3.1^{\circ}$ y $2^{\circ}$ ). 
$3^{\circ}$ être diffusées dans des médias ou des supports publicitaires connus pour s'adresser principalement aux mineurs d'âge;

$4^{\circ}$ être montrées dans un cinéma lors de la projection d'un film principalement destiné à un public composé de mineurs d'âge;

$5^{\circ}$ se dérouler dans des lieux où se réunissent principalement des mineurs d'âge ou dans des établissements de santé (art. 2.\$2).

- Utilización de equipos o actividades deportivas relacionados con actividades promocionales: "Les publicités en faveur des jeux de hasard et des paris exploités par les titulaires d'une licence de classe A+, $\mathrm{B}+$ ou $\mathrm{F} 1+$ via les instruments de la société de l'information ne peuvent pas: (...) $15^{\circ}$ mettre en scène des sportifs ou des clubs sportifs qui jouent à des paris ou des jeux de hasard” (art. 2.\$1. 15\%).

- Utilización de personajes célebres para los menores en actividades promocionales: "Pour les jeux de hasard qui sont exploités au moyen des instruments de la société de l'information par un titulaire de licence de classe A+, B+ et F1+, aucune publicité ne sera diffusée: (...) utiliser des dessins ou des techniques de marketing faisant référence à des personnages, des images ou des expressions populaires ou à la mode chez les mineurs (art. $3 . \$ 1 \mathrm{er} .6^{\circ}$ ) y "Les publicités, communications ou actions promotionnelles en faveur des jeux de hasard (...) ne peuvent pas: utiliser des dessins ou des techniques de marketing faisant référence à des personnages, des images ou des expressions populaires ou à la mode chez les mineurs (art. $3 \$ 3.3^{\circ}$ ).

Como resulta obvio apenas expuestas las medidas adoptadas, el objetivo principal de la reforma no es otro que el prevenir la lacra de la ludopatía en general y, de modo especial, en colectivos vulnerables, como son los menores de edad. Se entiende que esta sí es una norma que establece restricciones razonables y moderadas, que adopta medidas que concilian adecuadamente la libertad de empresa con la necesaria protección de los derechos de los usuarios, consciente de la existencia de problemas sociales cada vez más graves ante la imparable generalización del gambling.

Esta habría de ser la línea emprendida por el legislador español si, finalmente, tomara conciencia de la gravedad del problema planteado ${ }^{31}$

\section{3. Últimos movimientos legislativos}

El pasado mes de febrero el Ministerio de Consumo, respondiendo ya a cierta alarma social, publicó un Proyecto de Real Decreto de Comunicaciones Comerciales de las Actividades de Juego que, previ-

31. “(...) el 62,1\% de los menores de 18 años relata haber jugado a algún juego de azar durante los últimos meses, de entre los cuales, las apuestas deportivas y las quinielas son las más frecuentes. De entre los que juegan, el 22,6\% manifiestan entre uno y tres criterios de juego patológico del DSM-5, mientras que el 2,8\% muestran cuatro o más criterios, que es la cifra utilizada para el diagnóstico de juego patológico (...)”. 
siblemente, entrará en vigor este otoño ${ }^{32}$. Con el riego que supone comentar disposiciones de derecho proyectado, sí es cierto que la norma adelanta cuáles son, en principio, las intenciones del Gobierno respecto a la regulación del juego.

Una de las principales novedades es la limitación horaria para la publicidad emitida a través de medios audiovisuales, que únicamente podrá realizarse de 1 a 5 de la madrugada, habiendo de cumplir, además, con ciertas restricciones en cuanto a su contenido, entre las que destaca la prohibición de utilizar expresiones que induzcan a un uso compulsivo de los servicios promocionados, tales como "juega ya", "apuesta ahora", o similares.

Sin embargo, e independientemente de estas y otras limitaciones, que pudieran hacer pensar, por fin, en una reacción legislativa enérgica frente a esta lacra, quizás lo más relevante de la norma sean las excepciones que ésta articula a fin de permitir la actividad promocional en determinados ámbitos ${ }^{33}$. Así, resulta muy desalentadora la excepción que introduce el art. 19 del proyecto en relación con las retransmisiones en directo de acontecimientos deportivos, respecto de los cuales permite la publicidad prohibida siempre que aquellos tengan lugar a partir de las 20:00 y hasta las 5:00 horas y cumplan con algunos requisitos que resultan fácilmente soslayables. Esta excepción resulta especialmente dañina porque, en primer lugar, excluye de la prohibición a los espectáculos deportivos que, cuantitativamente, resultan más seguidos por el público en general en España (los partidos de la liga de fútbol de mayor audiencia se suelen programar en esa franja horaria, de igual forma que los de la Champions League siempre se emiten entre esas horas) y, en segundo lugar, porque son estas las competiciones que más interés suscitan en el público infantil y juvenil. En definitiva, la excepción consigue, paradójicamente, dejar sin efecto, desde un punto de vista material, la prohibición general articulada, plegándose, una vez más, a los intereses económicos existentes.

\section{CONCLUSIONES}

En este trabajo se ha pretendido exponer, de manera sucinta, el estado de la regulación publicitaria en tres ámbitos sectoriales que, por diferentes razones, se encuentran de singular actualidad.

32. Mariano Chóliz y Juan Lamas, “¡Hagan juego, menores! Frecuencia de juego en menores de edad y su relación con indicadores de adicción al juego", en Revista española de drogodependencias, nº. 42 (I), (2017): 34, acceso el 9 de julio de 2020, https://www.aesed.com/descargas/revistas/v42n1_juego.pdf

https://www.ordenacionjuego.es/sites/ordenacionjuego.es/files/noticias/20200224_proyecto_rd_comunicaciones_ comericales_juego.pdf, acceso el 29 de julio de 2020.

33. La norma permite, con ciertas limitaciones en cuanto a su contenido, la publicidad en prensa escrita y en diarios digitales, cuestión esta última que preocupa por la posibilidad que el usuario interesado va a tener de acceder, de forma inmediata, a la web promocionada, en la cual podrá ya, si lo desea, efectuar directamente su apuesta. La norma tampoco se ocupa de restringir, de forma efectiva, la publicidad de la lotería estatal o la de la ONCE, juegos ambos en los que no sólo se recurre a la promoción basada en el cambio de vida del jugador sino que, incluso, presentan un componente de inmediatez que sí se prohíbe en relación con las apuestas on line ("rasca" de la ONCE, por ejemplo). Se observa, por tanto, cierta asimetría de trato difícilmente justificable si, de verdad, se pretende atajar el problema del juego. 
Del resultado de tal análisis, y desde un punto de vista técnico, se observa que, tanto en el ámbito de la publicidad de las clínicas dentales como en el de las pseudoterapias, existen normas vigentes que, debidamente aplicadas, pueden perfectamente afrontar los problemas que, en tales sectores, se han evidenciado en los últimos tiempos. Se insiste en que la perspectiva bajo la que se ha desarrollado el estudio es la que atañe, únicamente, a los problemas derivados de una ejecución de la comunicación publicitaria contraria a derecho, sin atender a otras cuestiones que, como ya se ha señalado, pueden incidir en el problema general planteado pero que nada tienen qué ver con una insuficiencia en cuanto al control de posibles prácticas publicitarias ilícitas (intrusismo laboral, fraudes financieros, etc.).

Por el contrario, en el ámbito de la regulación del juego y las apuestas, se evidencia la existencia de una regulación publicitaria insuficiente, lo que se acredita por la vía de los hechos de la mano del imparable crecimiento de una patología como es la adicción al juego en edades tempranas.

Pues bien, tales conclusiones contrastan con los últimos movimientos políticos detectados, los cuales se muestran paradójicamente favorables a intervenir reformando, para agravarlo, el régimen jurídico de la publicidad sanitaria o pseudosanitaria y, sin embargo, poco o nada dicen acerca de la necesidad de endurecer la regulación del juego, lo que pondría fin o, al menos, minimizaría, los graves problemas sociales que se están produciendo a raíz del deficiente control de las prácticas promocionales en tal ámbito.

Lamentablemente, parece que, una vez más, los intereses corporativos canalizados a través de lobbies profesionales o empresariales han podido más que los derechos de colectivos de consumidores y usuarios particularmente vulnerables, pero sin apoyo económico suficiente.

\section{REFERENCIAS}

- $\quad$ "Acupuntura, reiki, homeopatía, yoga, quiromasaje y shiatsu, entre las pseudociencias que investiga el Gobierno". Diario Sur, 1 de marzo de 2019, acceso el 29 de junio de 2020, https://www.diariosur.es/sociedad/sanidad-ciencia-realizan-listado-pseudoterapias $-20190228123027-n t r c . h t m l$

- Chóliz, Mariano y Lamas, Juan. “¡Hagan juego, menores! Frecuencia de juego en menores de edad y su relación con indicadores de adicción al juego”. Revista española de drogodependencias, $\mathrm{n}^{\circ} .42$ (I), (2017): 34-47, acceso el 9 de julio de 2020, https://www.aesed.com/descargas/revistas/v42n1_juego.pdf.

- "El consejero de Sanidad de Madrid rechaza declarar a la homeopatía como pseudoterapia", en Diario El Boletín, 25 de marzo de 2019, acceso el 5 de julio de 2020, https://www.elboletin.com/noticia/172350/sanidad/el-consejero-de-sanidad-de-madridrechaza-declarar-a-la-homeopatia-como-pseudoterapia.html. 
- García Ruiz Pablo, Buil, Pilar y Solé Moratilla, María José. "Consumo de riesgo: menores y juegos de azar online. El problema del 'juego responsable” ”. Política y Sociedad, vol. 53, n² (2016): 551-575. https://doi.org/10.5209/rev_POSO.2016.v53.n2.47921

- Hernández Ruiz, Alejandra." La protección al consumidor en las webs de juego online de los operadores con licencia en España”. Adicciones, vol. 32, nº. 3, (2020): 216-224. https://doi.org/10.20882/adicciones. 1262

- López Rincón, Darío. "Gambling o juego regulado". ELDERECHO.COM LEFEBVRE, acceso el 14 de julio de 2020, https://elderecho.com/gambling-o-juego-regulado.

- "Nueva multa al «curandero» Pàmies: 600.000 euros por promocionar la lejía para combatir el autismo". Diario ABC, 16 de octubre de 2018, acceso el 3 de julio de 2020, https://www.abc.es/espana/catalunya/abci-nueva-multa-curandero-pamies-600000-eurospromocionar-lejia-para-combatir-autismo-201810261505_noticia.html.

- $\quad$ Ramírez, Lorenzo. "El Gobierno fracasa en su lucha contra el fraude sanitario de los falsos productos milagro". 65YMÄS.COM, 30 de marzo de 2019, acceso el 30 de junio de 2020, https://www.65ymas.com/sociedad/el-gobierno-fracasa-en-su-lucha-contra-el-fraudesanitario-de-los-falsos-productos-milagro_2008_102.html.

- "Retiran la publicidad que otorgaba propiedades milagrosas al aceite Fergus". Nuevatribuna.es, 26 de marzo de 2018, acceso el 1 de julio de 2020, https://www.nuevatribuna.es/articulo/consumo/retiran-publicidad-otorgaba-propiedadesmilagrosas-aceite-fergus/20180326181223150202.html

RECIBIDO : 30/07/2020

APROBADO: 15/09/2020 